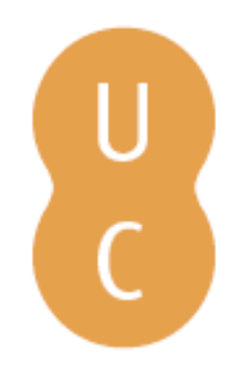

\title{
nommalina
}

\section{Otimização do escalonamento da produção na indústria de moldes: aplicação ao} caso da GECO

\author{
Autor(es): \\ Virgílio, Bárbara Esperança; Gomes, Marta Castilho; Póvoa, Ana \\ Barbosa
}

Publicado por: Imprensa da Universidade de Coimbra

URL persistente:

URI:http://hdl.handle.net/10316.2/35926

DOI:

DOI:http://dx.doi.org/10.14195/978-989-26-0738-2_6

Accessed : $\quad$ 26-Apr-2023 06:22:22

A navegação consulta e descarregamento dos títulos inseridos nas Bibliotecas Digitais UC Digitalis, UC Pombalina e UC Impactum, pressupõem a aceitação plena e sem reservas dos Termos e Condições de Uso destas Bibliotecas Digitais, disponíveis em https://digitalis.uc.pt/pt-pt/termos.

Conforme exposto nos referidos Termos e Condições de Uso, o descarregamento de títulos de acesso restrito requer uma licença válida de autorização devendo o utilizador aceder ao(s) documento(s) a partir de um endereço de IP da instituição detentora da supramencionada licença.

Ao utilizador é apenas permitido o descarregamento para uso pessoal, pelo que o emprego do(s) título(s) descarregado(s) para outro fim, designadamente comercial, carece de autorização do respetivo autor ou editor da obra.

Na medida em que todas as obras da UC Digitalis se encontram protegidas pelo Código do Direito de Autor e Direitos Conexos e demais legislação aplicável, toda a cópia, parcial ou total, deste documento, nos casos em que é legalmente admitida, deverá conter ou fazer-se acompanhar por este aviso.

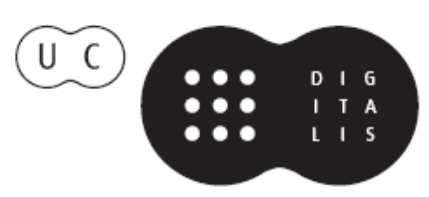




\section{INVESTIGAÇÃO OPERACIONAL EM AÇÃO \\ CASOS DE APLICAÇÃO}

RUI CARVALHO OLIVEIRA JOSÉ SOEIRO FERREIRA (EDITORES)

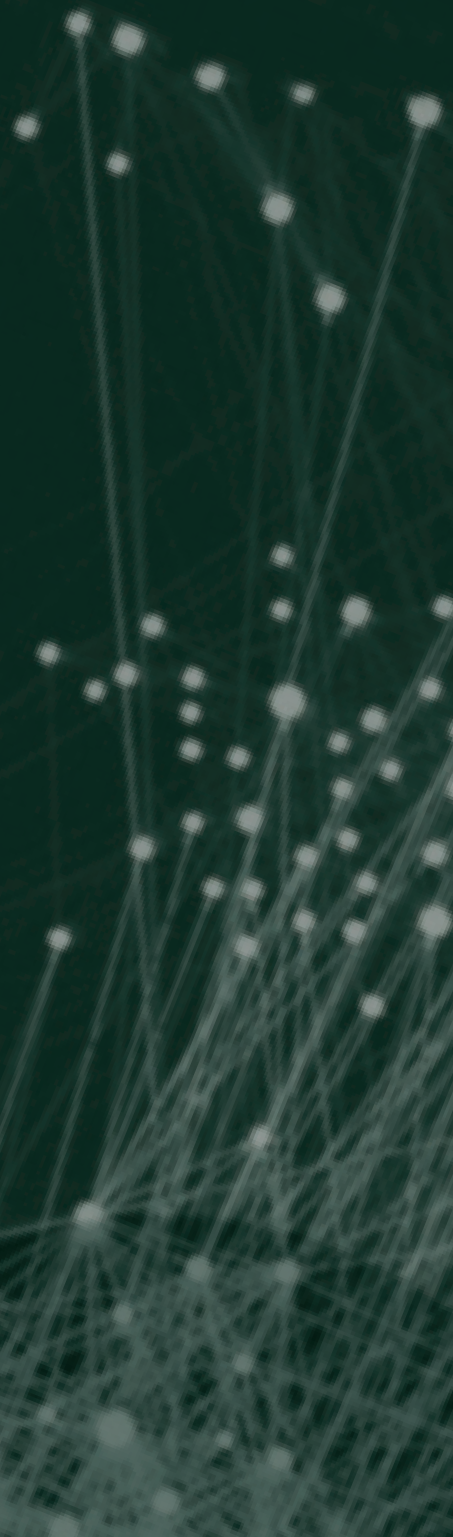




\section{CASO 6}

\section{O'TIMIZAÇÃO DO ESCALONAMENTO DA PRODUÇÃO NA INDÚSTRIA DE MOLDES: AplicaÇÃo ho CASO dA GECO}

Bárbara Esperança Virgílio

esperanca.barbara@gmail.com

Marta Castilho Gomes

CESUR - Instituto Superior Técnico Universidade de Lisboa marta.gomes@tecnico.ulisboa.pt

Ana Barbosa Póvoa CEG-IST - Instituto Superior Técnico Universidade de Lisboa apovoa@tecnico.ulisboa.pt 


\section{RESUMO}

A indústria de moldes tem um papel de relevo no mundo atual, pois o fabrico de uma multiplicidade de objetos presentes na nossa vida diária depende da utilização de moldes. A produção destas ferramentas é um processo de alta tecnologia com grande implantação em Portugal, sendo o nosso País um dos maiores exportadores de moldes a nível mundial. A diminuição constante do ciclo de vida dos produtos e o aumento de competitividade do mercado tem obrigado as empresas do setor a melhorarem o seu desempenho, através do aumento da eficiência dos processos. Neste incremento, revela-se crítica a tarefa do planeamento e escalonamento da produção, a qual é ainda realizada por métodos tradicionais em muitas empresas de moldes.

Neste trabalho desenvolveu-se um modelo de programação linear inteira OPTMESC - para resolver o problema do escalonamento da produção no setor dos moldes, que corresponde a uma indústria de produção discreta por encomenda do tipo job shop. O modelo foi implementado na linguagem de modelação GAMS e resolvido com um solver comercial para dados reais recolhidos na empresa GECO. Inclui-se um exemplo ilustrativo de aplicação do modelo (de reduzida dimensão) e um caso de estudo que consiste na obtenção de um plano de produção da empresa envolvendo peças de vários moldes. Para este último efetuou-se uma análise pós-otimização aos parâmetros mais relevantes do modelo. Os tempos computacionais obtidos são compatíveis com a frequência com que o problema é resolvido na fábrica. Assim, este estudo apresenta-se como um promissor primeiro passo no desenvolvimento de um sistema computacional de apoio ao escalonamento da produção na indústria de moldes.

\section{PALAVRAS-CHAVE}

Escalonamento na indústria de moldes, Produção por encomenda, Programação linear inteira, Problemas job shop. 


\section{Introdução}

A produção orientada para o cliente é, cada vez mais, uma questão central em empresas de produção por encomenda. Esta orientação, e consequentemente a maior interação entre os sistemas de produção e o cliente, criam grandes desafios e necessidades de soluções inovadoras, quer ao nível da organização do processo produtivo e das tecnologias utilizadas, quer ao nível dos sistemas de planeamento e controlo da produção. O trabalho aqui descrito surge neste contexto, pretendendo estudar formas de melhoria do processo de escalonamento na GECO, uma empresa produtora de moldes.

O fabrico de moldes é uma indústria de alta precisão indispensável à produção de uma ampla diversidade de produtos do nosso quotidiano. Trata-se contudo de uma indústria praticamente desconhecida do grande público tal como refere Lopes (2000):

"A indústria de moldes está presente na caixa que suporta o ecrã da nossa televisão, na cadeira de jardim em que nos sentamos, no aspirador que temos em casa... Está lá, mas nós não a conseguimos ver, porque os moldes que deram origem a estes objetos continuam fechados nos pavilhões onde se processa o respetivo fabrico (...) É uma indústria que causa uma certa estranheza pelas suas dimensões. Quem imaginaria que um molde para um contentor de lixo pode pesar 40 toneladas ou que um molde para uma mala de viagem pode custar 50 mil contos?"

Em Portugal, o peso da indústria de moldes na economia é muito relevante, não só pelo volume de negócios que movimenta mas também por se tratar de um setor de excelência em que o nosso País se destaca a nível mundial. As empresas produtoras de moldes são tipicamente pequenas e médias empresas (PMEs) que atuam como parceiras das empresas de moldagem, geralmente grandes empresas que no contexto português se encontram essencialmente nos setores da indústria automóvel, de embalagem, eletrónica, de telecomunicações e de eletrodomésticos.

A indústria de moldes tipicamente trabalha em modo de produção por encomenda, onde o produto (molde) é concebido individualmente de acordo com as especificações do cliente (situação designada "one-of-a-kind production" na literatura). O intervalo de tempo para projetar e fabricar um molde tem 
vindo a diminuir consideravelmente à medida que o ciclo de vida dos produtos obtidos por moldagem se torna mais curto. Desta forma, para melhorar a competitividade, muitas empresas de produção de moldes estão a desenvolver soluções para aumentar a eficiência dos seus processos, otimizando tempo e custos (Ni et al., 2007), onde se inclui o desenvolvimento de ferramentas computacionais para apoiar o planeamento e escalonamento da produção.

O escalonamento é uma decisão de um processo produtivo que determina quando, onde e como produzir um conjunto de produtos obedecendo a um conjunto de requisitos num horizonte de tempo dado. O seu objetivo, em geral, corresponde à minimização do tempo total de processamento (makespan), à maximização do lucro ou à minimização de custos, no horizonte de tempo especificado (Floudas \& Lin, 2004). Sendo uma função crítica para a melhoria do desempenho produtivo (Méndez et al, 2006), o escalonamento da produção é um problema complexo que exige a aplicação de modelos de otimização, de técnicas heurísticas ou de simulação na sua resolução. Ao contrário de outras indústrias de produção discreta como sejam o fabrico de chips eletrónicos e de semicondutores, para as quais existe na literatura científica um vasto número de artigos abordando os respetivos problemas de planeamento e escalonamento da produção, verifica-se que para a indústria de moldes são escassos os trabalhos nesta área. De facto, Choy et al. (2011) afirmam que nesta indústria o escalonamento da produção é ainda normalmente efetuado por métodos tradicionais, e é essa a experiência das autoras no contato com empresas portuguesas do setor.

Assim, este trabalho teve como objetivo principal o desenvolvimento de um modelo de programação linear inteira para o apoio ao escalonamento da produção na indústria de moldes e a sua resolução com dados reais fornecidos por uma empresa (GECO). As decisões contempladas no modelo dizem respeito à afetação, ou atribuição, das operações às máquinas existentes no shop floor e a afetação no tempo (escalonamento) da produção de cada peça e dos moldes (conjuntos de peças) tendo em conta o cumprimento das datas de entrega acordadas com os clientes.

A organização deste texto é a seguinte: na secção 2 apresenta-se a contextualização do problema, efetuando-se na secção 3 uma revisão sumária 
da literatura de escalonamento de job shop, com particular ênfase nos métodos de programação matemática. A secção 4 descreve em pormenor o modelo de programação linear inteira desenvolvido (OPTMESC) ilustrando-se a sua aplicação com um exemplo de reduzida dimensão. O modelo é resolvido na secção 5 com dados recolhidos na GECO, a que se segue uma análise pósotimização aos parâmetros mais relevantes. A última secção (6) apresenta as conclusões do estudo e hipóteses de evolução futura do trabalho.

\section{Contextualização do problema}

Após uma perspetiva sumária da indústria de moldes em Portugal, descrevese a constituição de um molde assim como o respetivo processo de fabrico. Segue-se uma breve apresentação da empresa GECO e uma descrição do processo de planeamento e escalonamento do fabrico de moldes atualmente em uso na mesma.

\subsection{A indústria de moldes em Portugal}

A indústria de moldes nasceu em Portugal no início do século XX, associada à indústria vidreira. Atualmente existem dois polos, nas regiões Centro e Norte do País - concelhos da Marinha Grande e Oliveira de Azeméis, respetivamente. Conta com cerca de 530 empresas, na sua maioria PMEs, e emprega aproximadamente 8250 trabalhadores. É considerada uma indústria metalomecânica pois incorpora todos os segmentos responsáveis pela transformação de metais nos produtos desejados.

O valor da exportação de moldes atingiu cerca de 364 milhões de euros em 2011, ano em que o valor total de produção foi cerca de 404 milhões de euros, ou seja, Portugal exportou mais de $90 \%$ da produção total. Os principais destinos dos moldes portugueses em 2011 foram a Alemanha (25\%), França (18\%), Espanha (17\%), Brasil (4\%), Polónia (3\%), E.U.A. (3\%) e México (3\%). A dimensão internacional da indústria é bem patente no facto das vendas se terem destinado a 75 países distintos. O mercado de exportação de moldes, entre 2000 e 2011, registou uma diminuição da exportação que se deve em parte ao facto da indústria nacional, principalmente os plásticos, ter aumentado fruto do alargamento da cadeia de valor das empresas de moldes. De 
mencionar ainda que o setor automóvel se tornou o principal dinamizador tanto a nível tecnológico como financeiro desta indústria, totalizando cerca de 14\% do volume de produção total em 1991 e 72\% em 2010. Finalmente, numa comparação com outros países, Portugal ocupava em $2004^{1}$ a nona posição no ranking mundial de países exportadores de moldes (com uma quota de 3,6\%) sendo o terceiro maior exportador a nível europeu (IAPMEI 2006).

Para colocar o setor dos moldes em Portugal numa nova senda de crescimento, com vista a torná-lo num líder mundial, a Sociedade Portuguesa de Inovação iniciou o desenvolvimento de um projeto estruturante a médio e longo prazo, envolvendo todas as partes interessadas (stakeholders): empresas, associações, centros tecnológicos, universidades e decisores políticos. A concretização deste projeto estruturante começou pelo planeamento estratégico do qual resultou o Plano Estratégico para o Setor dos Moldes em Portugal (2008).

Este estudo destaca o papel das universidades como fundamental para o aumento das capacidades e competências do setor dos moldes, quer ao nível da transferência de tecnologia quer ao nível da formação de quadros técnicos e de gestão. A indústria beneficiará ainda da interação existente entre as universidades e outros parceiros a nível internacional. Apesar da relação com a Academia tomar na atualidade diferentes formas, várias empresas do setor consideram existir insuficiente colaboração ao nível dos programas de ensino e no desenvolvimento de soluções técnicas para a engenharia de produto, produção ou o desenvolvimento de novos materiais. Surge assim a necessidade crescente de criação de um mecanismo de transferência de tecnologia e de conhecimento entre o setor empresarial e os centros de saber, que permita à indústria desenvolver produtos inovadores e ajustar-se aos ciclos de vida reduzidos dos produtos.

\subsection{Descrição e processo de fabrico de um molde}

Existem diferentes tipos de moldagem mas todos se podem resumir ao mesmo procedimento básico: o material que se pretende moldar é colocado, quente ou pré-aquecido, dentro do molde e através da compressão e/ou da

\footnotetext{
${ }^{1}$ Dados de contexto internacional mais recentes a que foi possível aceder.
} 
ocorrência de reações químicas, endurece e adquire a forma pretendida. A figura 1 ilustra a moldagem por compressão de uma peça de plástico.
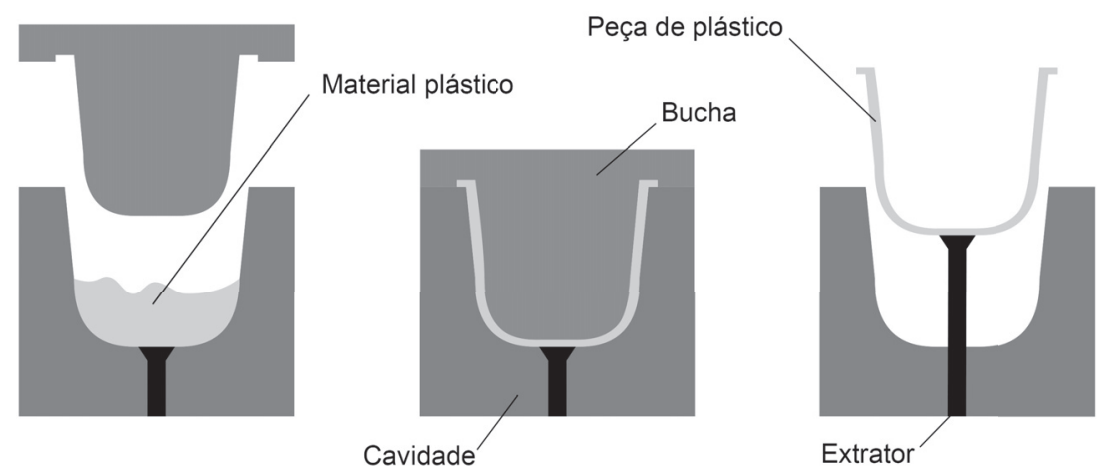

Figura 1: Funcionamento de um molde (moldagem por compressão).

Um molde é uma ferramenta constituída por diversas peças. A estrutura é a parte que serve de suporte ao molde. A cavidade é a parte côncava do molde, na qual é injetado, ou depositado, o material a moldar. A bucha é a parte convexa ou saliente do molde, por onde se efetua a extração da peça moldada. Os elementos móveis (localizados na maior parte dos casos na bucha) são elementos que se deslocam na horizontal através de uma guia (montada do lado da cavidade), durante a abertura do molde, para se poder extrair a peça moldada. Os balancés têm uma função semelhante aos elementos móveis mas deslocam-se na vertical (segundo um determinado ângulo) com a ajuda das chapas de extração permitindo a desmoldagem de peças com determinado tipo de orifícios, designados "zonas negativas". Os postiços são colocados em zonas de difícil polimento, zonas para as quais o cliente pretende uma dureza diferente ou zonas a retificar ou a alterar posteriormente (do ponto de vista das dimensões). Por fim, os acessórios são peças que não terão contato com o material a moldar (plástico ou outro) mas que são montados na estrutura para um bom funcionamento do molde. A figura 2 apresenta diferentes perspetivas de um molde produzido na empresa GECO, onde se pode apreciar a complexidade do conjunto de peças que o constitui. 
A figura 3 esquematiza as diferentes etapas do processo produtivo de um molde. Primeiramente decorre a fase de projeto do molde, em estreito contato com o cliente até que este aprove o desenho final. Dá-se então início ao fabrico propriamente dito, com a operação de galgamento que consiste no primeiro desbaste do bloco de aço, de modo a que as suas dimensões se aproximem das requeridas. O desbaste é uma operação destinada a remover material de modo a criar um esboço de geometria final da peça, deixando-a com uma espessura extra de $0,5 \mathrm{~mm}$, para posterior acabamento. Na fase seguinte executam-se na peça as furações necessárias: de fixações, extração e águas. O tratamento térmico destina-se a conferir ao molde maior tenacidade e resistência ao uso; sendo um processo bastante dispendioso só é feito se o cliente exigir. Na operação de retificação anulam-se possíveis empenos (deformações) que a peça possa ter ganho no desbaste. No final desta operação a peça deve ter as cotas definidas no desenho (projeto). A fresagem final ${ }^{2}$ destina-se a remover a sobreespessura de material deixada na fresagem de desbaste, de modo a deixar a peça com o acabamento e as dimensões pretendidas. Se não for possível definir uma determinada zona da peça por fresagem recorre-se à erosão (eletroerosão). No controlo verificamse as medidas finais de cada peça do molde, e se todas as operações foram completadas de acordo com o desenho do molde. Acabada a produção de todas as peças, procede-se à operação de montagem, podendo-se em seguida testar o molde. O embarque só tem lugar quando as amostras (peças moldadas) provenientes dos testes são do agrado do cliente.

\footnotetext{
${ }^{2}$ Esta poderá ser fresagem CNC (Comando Numérico Computorizado) ou DNC (Controlo Numérico Direto). A fresagem CNC é realizada por programação direta da máquina e só se usa em operações geometricamente simples. A fresagem DNC utiliza um software computacional que calcula cada cota necessária para a fabricação da peça através do seu desenho 3D e passa essa informação para a máquina automaticamente. Este é um processo mais atual e eficiente que veio substituir a fresagem CNC.
} 


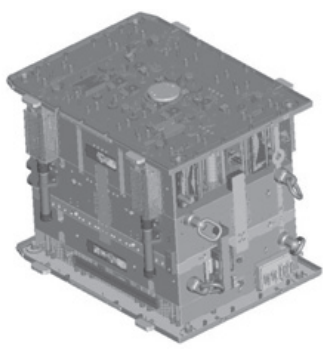

A

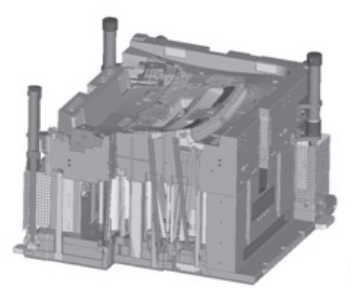

D

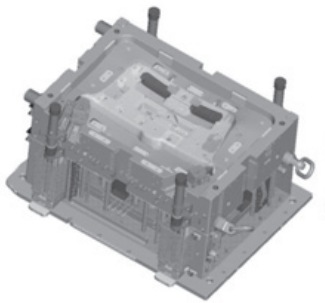

B

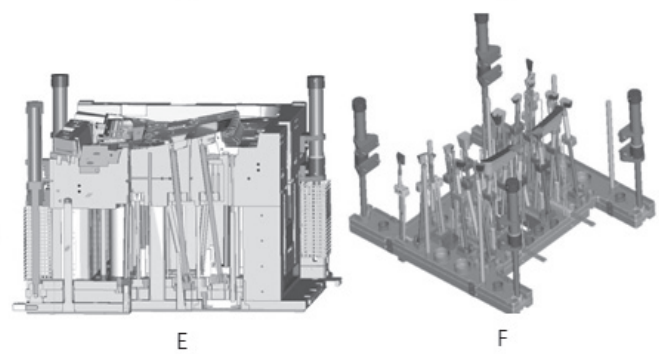

Figura 2: Diferentes perspetivas de um molde produzido na GECO.

A - Molde completo fechado; B - Bucha; C - Cavidade; D, E - Corte na bucha; F - Chapa de extração com os balancés

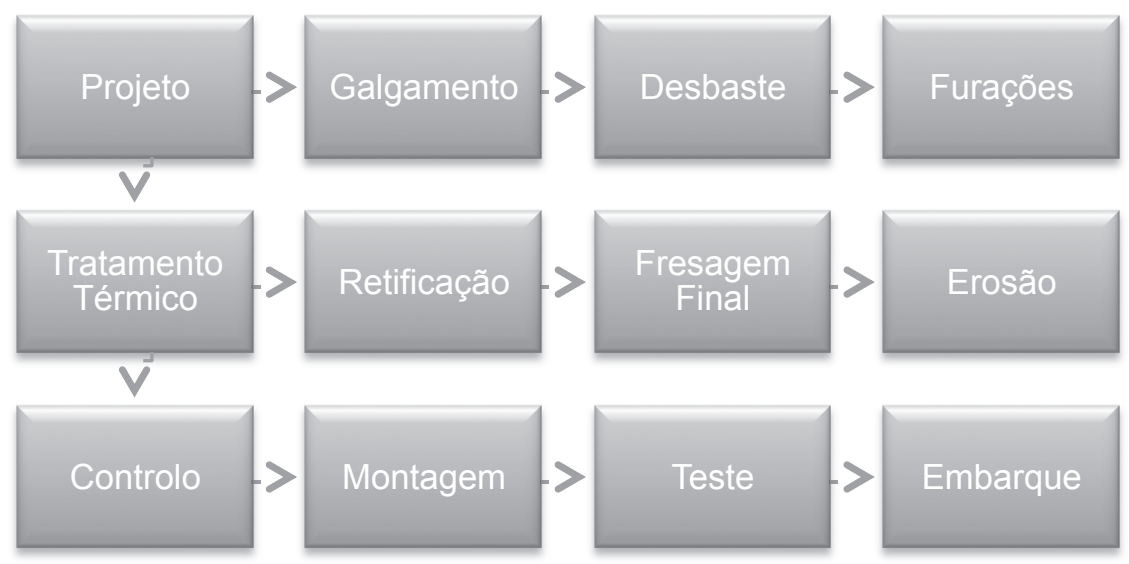

Figura 3: Processo de fabrico de um molde. 


\subsection{A empresa GECO}

A empresa GECO iniciou a sua atividade em 1969 como Agente de Moldes e em 1975 tornou-se uma sociedade de Quotas de Responsabilidade Limitada com a denominação GECO (Gabinete Técnico e Controlo de Moldes em Fabricação, Lda.). Situada no Telheiro, freguesia de Maceira, distrito de Leiria, a GECO é uma sociedade de cariz familiar especializada no fabrico de moldes de injeção para a indústria de plásticos (termoplásticos, bi-componentes e injeção assistida a gás). A sua missão é:

"Transformar qualquer projeto numa ferramenta capaz de satisfazer as necessidades do cliente".

O negócio cresceu e a empresa atualmente faz parte de um grupo industrial que integra fábricas autónomas e fábricas que apoiam a GECO na produção de moldes (unidades especializadas no fabrico de determinados tipos de peças ou na realização de certas operações). Ocupando uma área de $16.200 \mathrm{~m}^{2}$, a empresa possui 316 funcionários dedicados à fabricação e comercialização de moldes. A produção destina-se à indústria automóvel (80\% da produção total), eletrónica, de embalagem, farmacêutica e de equipamentos domésticos. Além das fábricas em Portugal a empresa possui unidades no Reino Unido, México e Brasil e escritórios na Alemanha, E.U.A. e Rússia. As fábricas situadas no estrangeiro providenciam apoio aos clientes, não se dedicando ao fabrico de moldes. Atualmente a empresa exporta praticamente toda a sua produção, tendo o volume de negócios sido de 14 milhões de euros em 2013.

\subsection{Planeamento e escalonamento na GECO}

Com o decorrer do tempo e com a evolução da tecnologia, os moldes produzidos na GECO foram tomando formas cada vez mais complexas, em resposta às necessidades dos clientes. Esta complexidade permitiu à empresa entrar em mercados novos aumentando substancialmente a produção total. Neste contexto, para cumprir as datas de entrega há que planear rigorosamente todo o processo produtivo dos moldes.

O planeamento e escalonamento inicia-se com a chegada da encomenda de um novo molde, pois só desta forma é que pode ser fornecido ao cliente um orçamento bem preparado. Os líderes de projeto (LP) averiguam as hipóteses 
de produção do molde, tanto a nível de requisitos técnicos e de materiais, como de prazo, sendo a negociação com o cliente efetuada a partir destes dados. A cotação entregue ao cliente menciona o tipo de aço recomendado, os sistemas de injeção e de extração, acabamentos de superfícies e outras informações importantes referentes ao fabrico do molde. Após formalizada a encomenda, efetua-se o desenho preliminar do molde que o cliente deverá verificar, comentar e finalmente aprovar. Depois desta aprovação procede-se à encomenda do aço, iniciam-se os desenhos das peças e faz-se o escalonamento da produção.

Na GECO, o processo de planeamento e escalonamento da produção é efetuado pelo diretor de produção, designado líder de grupo (LG), de forma manual, recorrendo à folha de cálculo Excel e ao software Microsoft Project para armazenamento e visualização dos dados. As decisões do escalonamento são pois tomadas sem o recurso a um algoritmo de ordenação de tarefas implementado computacionalmente. Ao realizar esta tarefa o LG dá prioridade às peças dos moldes que constituem os fatores limitativos da entrega (bucha, cavidade e estrutura). Os LG também são responsáveis pelos vários setores de produção, tendo sempre conhecimento de como estão a decorrer as operações de fabrico. Semanalmente têm lugar reuniões entre os LP e os LG para apurar a situação em que se encontra a produção dos vários moldes e discutir modificações necessárias, de forma a minimizar erros e diminuir o tempo total de produção. No caso de não existir capacidade interna para realizar determinadas operações nos prazos estabelecidos, decide-se sobre o recurso a horas extraordinárias, ao apoio de outros complexos industriais do mesmo grupo empresarial ou à subcontratação de determinadas operações.

Durante o fabrico dos moldes é frequente surgirem erros que necessitam correção. Estes são muitas vezes detetados na fase de teste, quando a peça de plástico moldada não se apresenta como o cliente deseja. Os erros podem ter diversas origens: erros de projeto do molde, de programação das máquinas de fresagem DNC ou erros dos operadores das máquinas (por exemplo, troca no tamanho das ferramentas para a maquinação da peça ou engano no ângulo da furação da peça). Estes erros provocam atrasos no processo produtivo podendo comprometer as datas de entrega acordadas com os clientes. Do 
ponto de vista do escalonamento da produção, este deve permitir acomodar operações adicionais de correção de erros quando necessário, de forma a observar os prazos.

A empresa GECO é bastante exigente no cumprimento das operações planeadas para as diversas fases de fabrico do molde, pois só assim poderá ir ao encontro da data de entrega com o máximo de rigor e qualidade. O tempo total de produção depende mais da complexidade do molde do que da sua dimensão, estando o cliente por vezes disposto a pagar um valor adicional para diminuir o prazo de entrega do molde.

Desta forma se entende como a função do planeamento e escalonamento da produção é crítica nesta indústria, não existindo atualmente na GECO qualquer sistema de apoio à decisão que a suporte.

\section{Revisão da literatura}

$\mathrm{Na}$ indústria podem-se identificar duas estratégias principais de produção: flow shop e job shop. A operação flow shop está normalmente associada à produção repetitiva ou contínua e é frequentemente caracterizada por elevados volumes de produção, grande uniformização, leques reduzidos de produtos e elevada taxa de automação. Já a operação job shop está tipicamente ligada à produção em descontínuo e fabrico por encomenda. Neste caso o leque de produtos é frequentemente diversificado, com volumes de produção reduzidos e a existência de diferentes sequências ou rotas de produção.

Os problemas de escalonamento em indústrias de produção discreta do tipo job shop têm atraído cada vez mais investigadores devido à sua generalidade e dificuldade inerente. O problema de escalonamento de job shop clássico, em que existe uma única máquina por operação, tem sido intensivamente estudado na literatura de Investigação Operacional. Todavia, como notam Tay \& Ho (2008), na prática a configuração do shop floor consiste em diversas cópias das máquinas mais críticas de forma a reduzir os estrangulamentos devidos a operações longas ou à ocupação das máquinas. Além disso, em sistemas de produção complexos, uma tarefa (job) pode visitar uma máquina mais do que uma vez o que é designado recirculação ou re-entrant process na literatura. 
Jain \& Meeran (1999) e mais recentemente Potts \& Strusevich (2009) apresentam revisões da literatura relativamente aos métodos de resolução que têm sido propostos para o problema do escalonamento de job shop. Da análise da literatura ressalta que, embora a maioria dos autores apresente formulações de programação matemática para o escalonamento de job shop, recorre a heurísticas para resolver o problema; o interesse por métodos de resolução baseados em programação matemática é bastante recente (Gomes, 2007).

Uma das principais vantagens deste tipo de métodos é a flexibilidade de modelação dos problemas de escalonamento, tornando relativamente simples o uso de várias funções objetivo e a incorporação de diferentes restrições na análise de um problema. Embora permitam obter a solução ótima, os modelos de programação matemática para o escalonamento de job shop possuem contudo a desvantagem dos tempos de computação necessários para a sua resolução crescerem exponencialmente com o aumento da dimensão dos problemas, o que se deve ao facto dos algoritmos aplicados, do tipo ramificação-e-limite ${ }^{3}$, serem algoritmos de enumeração implícita ${ }^{4}$. Assim, este é um método exato de resolução do problema, por oposição aos métodos aproximados (Gomes, 2007). Não obstante, a evolução dos recursos computacionais, tanto do ponto de vista do hardware como do software disponível, tem vindo a permitir resolver modelos de programação matemática de dimensão crescente.

Uma questão chave na modelação de problemas de escalonamento em programação matemática diz respeito à representação do tempo. Os modelos podem ser classificados em duas categorias principais (Méndez et al., 2006): modelos de tempo discreto e modelos de tempo contínuo, dependendo da divisão do horizonte de escalonamento ser efetuada em intervalos de tempo uniformes ou em intervalos de diferente dimensão. Gomes et al. (2005), Pan \& Chen (2005) e Ozguven et al. (2010) aplicaram a programação matemática na

\footnotetext{
${ }^{3}$ Branch-and-bound em inglês.

${ }^{4}$ Algoritmos que analisam o espaço de soluções (admissíveis) de um problema combinatório de forma inteligente, evitando a enumeração explícita de todas as soluções. Em geral os softwares comerciais disponíveis combinam dois métodos de pesquisa do espaço de soluções: o branchand-bound e a geração de planos de corte.
} 
resolução de problemas de escalonamento de job shop: o primeiro trabalho apresenta modelos de tempo discreto enquanto os outros dois propõem formulações de tempo contínuo.

Por fim, a revisão da literatura efetuada mostrou ser reduzido o número de trabalhos que abordam especificamente o planeamento e escalonamento da produção na indústria de moldes. Ni et al. (2007) desenvolveram um modelo de informação de negócio para a integração de processos na indústria de moldes, de modo a racionalizar as atividades de negócio e maximizar o desempenho global. Choi \& You (2006) apresentam uma extensa análise de desempenho de regras de despacho heurísticas para o escalonamento dinâmico destas indústrias, tendo recorrido para o efeito à simulação de eventos discretos. Choy et al. (2011) propuseram um modelo de apoio à decisão híbrido, combinando um algoritmo genético e um módulo de otimização.

\section{Modelo de programação matemática para escalonamento na indústria de moldes}

Esta secção descreve o modelo de programação linear inteira desenvolvido para o escalonamento da produção na empresa GECO, doravante designado OPTMESC $^{5}$. Este baseia-se no modelo de tempo discreto descrito por Gomes et al. (2005) e Gomes (2007), que foi alterado e adaptado tendo em conta as características do caso de estudo em análise. O modelo mantém características genéricas que possibilitarão a sua utilização, com o mínimo de adaptações, no escalonamento de outras indústrias de produção discreta do tipo job shop por encomenda, nomeadamente indústrias que não sejam do tipo "one-of-a-kind". A aplicação do modelo OPTMESC é ilustrada com um exemplo de reduzida dimensão.

\subsection{Definição do problema}

Previamente à apresentação do modelo, é necessário definir o problema em estudo. A caracterização que se segue incorpora já algumas especificidades do

\footnotetext{
${ }^{5}$ Sigla derivada da expressão "Optimização do Escalonamento de Moldes", com rearranjo das letras.
} 
modelo OPTMESC, nomeadamente a nível de nomenclatura e elementos que o constituem.

- Um molde $(k)$ é constituído por várias peças $(p)$, que diferem de molde para molde.

- Em geral, num molde as peças são únicas, mas podem existir algumas peças exatamente iguais, isto é, duas ou mais cópias da mesma peça ${ }^{6}$. Nesse caso, o modelo considera-as como duas ou mais unidades de uma mesma peça: são modeladas em conjunto, a nível de variáveis de decisão.

- A cada peça $(p)$ corresponde desta forma um número $\left(Q_{p}\right)$ de unidades idênticas a produzir (número inteiro: 1, 2, 3, etc.)

- Cada peça $(p)$ segue uma sequência ou rota de produção $(j)$. Peças diferentes podem seguir a mesma sequência de produção $(j)$.

- Uma sequência de produção $(j)$ é constituída por várias operações em sequência. São exemplos de operações o desbaste, furações, retificação e acabamento.

- Embora exista um fluxo genérico de operações, descrito em 2.2 e representado na figura 3, nem todas as operações estão presentes na sequência de produção de uma peça concreta. Para compreender este aspeto, é útil visualizar a figura 4 (na secção 4.3) onde se representam as sequências de produção para o conjunto de peças de um exemplo ilustrativo de aplicação do modelo.

- Cada operação $(o)$ deve ser realizada por uma máquina $(m)$.

- Existem diferentes máquinas $(m)$ disponíveis para realizar uma dada operação (o). Além disso, uma máquina $(m)$ pode executar diferentes operações. Por exemplo, uma máquina que realize o desbaste pode também executar o acabamento de estruturas.

- $\quad$ No modelo, cada operação (o) é precedida de um buffer ou fila de espera onde as peças aguardam para serem processadas. O buffer é comum a todas a máquinas que podem realizar essa operação.

\footnotetext{
${ }^{6}$ Por exemplo, duas buchas e duas cavidades iguais, o que permitirá produzir duas peças moldadas em simultâneo de cada vez que o molde é usado.
} 
- A descrição do modelo recorre à noção de buffer inicial (da primeira operação), buffers intermédios (das restantes operações) e buffer final (de peças acabadas) de cada sequência de produção. A figura 4 representa a alternância de buffers e operações nas sequências de produção do exemplo ilustrativo.

- As máquinas $(m)$ caracterizam-se pela operação ou operações que executam, os tempos de produção e a capacidade (número total de unidades que podem processar em simultâneo).

- $\quad$ Os tempos de produção $\left(T_{\text {pom }}\right)$ dependem da peça $(p)$, da operação $(o)$ e da máquina $(m)$. Além disso, tomam valores inteiros uma vez que o modelo de escalonamento é de tempo discreto.

- $\quad$ Para cada molde $(k)$ existe uma data de entrega $\left(D_{k}\right)$.

- A produção das peças $(p)$ deve ser escalonada para atender às datas de entrega $\left(D_{k}\right)$ do conjunto de moldes $(k)$ a que pertencem.

O modelo (OPTMESC) irá definir a afetação das máquinas na produção dos moldes de forma a cumprir as datas de entrega acordadas com os clientes, tanto quanto possível, num modo de operação just-in-time.

\subsection{Formulação matemática}

A formulação matemática proposta - OPTMESC - modela o problema descrito anteriormente: problema de escalonamento de job shop flexível em indústrias de produção discreta por encomenda. A formulação descrita nas secções 4.2.1 a 4.2.4 não incorpora explicitamente a operação de montagem das peças do molde; tal é feito na extensão do modelo apresentada em 4.2.5. Note-se que nenhuma das formulações considera as etapas de teste e embarque referidas na secção 2.2.

\subsubsection{Conjuntos e indices}

O modelo recorre à seguinte definição de conjuntos e índices:

$\begin{array}{lll}K & \text { moldes a escalonar } & k \in K \\ P & \text { peças a produzir } & p \in P \\ J & \text { sequências de produção } & j \in J\end{array}$




$\begin{array}{lll}O & \text { operações } & o \in O \\ M & \text { máquinas } & m \in M \\ P_{j} & \text { peças que seguem a sequência de produção } j & P_{j} \subset P \\ P_{k j} & \text { peças pertencentes ao molde } k_{j} & \\ & \text { que seguem a sequência de produção } & P_{k j} \subset P_{j} \\ J_{k} & \text { sequências de produção associadas ao molde } k & J_{k} \subset J \\ O_{j} & \text { operações na sequência de produção } j & O_{j} \subset O \\ O_{m} & \text { operações que podem ser realizadas na máquina } m & O_{m} \subset O \\ M_{O} & \text { máquinas que podem realizar a operação } o & M_{o} \subset M \\ T & \text { tempo } & t \in T\end{array}$

$O_{j}$ é um conjunto de elementos ordenados, sendo o aspeto da ordenação irrelevante no caso dos restantes conjuntos. Desta forma, para cada elemento (operação) de $O_{j}$ estão definidas as operações antecessora e sucessora; excetuam-se a primeira operação da sequência, sem antecessora, e a última, sem sucessora. A ordenação de $O_{j}$ torna-se necessária na escrita de certas restrições do modelo (restrições [7]).

Definem-se ainda os seguintes elementos particulares de cada sequência da produção:

$f_{j} \quad$ primeira operação ("first") na sequência de produção $j$

$l_{j} \quad$ última operação ("last") na sequência de produção $j$

\subsubsection{Parâmetros}

$H$ duração do horizonte de escalonamento, expressa em número de intervalos de tempo unitários

$Q_{p} \quad$ quantidade (número de unidades idênticas) da peça $p$ a produzir

$D_{k}$ data de entrega do molde $k$ (corresponde a um instante do horizonte de escalonamento $)^{7}$

$C_{m} \quad$ capacidade da máquina $m$ (número de unidades)

$S_{o}$ capacidade do buffer da operação $o$ (número de unidades)

\footnotetext{
${ }^{7}$ Nesta formulação do modelo corresponde ao instante em que se pretende que todas as peças do molde fiquem concluídas (prévio à montagem).
} 
$T_{\text {pom }}$ tempo de produção da peça $p$ na máquina $m$, para a operação $o$ (valor inteiro)

$N_{k}$ penalidade por não terminar a produção de uma peça do molde $k$ no horizonte de escalonamento definido

$Z_{k} \quad$ penalidade por uma peça do molde $k$ se encontrar em espera num buffer intermédio (por unidade da peça e por unidade de tempo)

$A_{k}$ penalidade pelo atraso na produção de uma peça do molde $k$, face à data de entrega (por unidade da peça e por unidade de tempo)

$B_{k} \quad$ penalidade por terminar a produção de uma peça do molde $k$ antes da data de entrega (por unidade da peça e por unidade de tempo)

O horizonte de escalonamento é dividido em $H$ intervalos de tempo de duração uniforme, visto que o modelo é de tempo discreto. Para a definição das restrições do modelo torna-se necessário definir um conjunto $T$ de instantes no tempo mais abrangente:

$$
\mathrm{T}=\left\{-t_{\max },-t_{\max }+1,-t_{\max }+2, \ldots,-2,-1,0,1,2, \ldots, H, H+1\right\} .
$$

Nesta definição, $t_{\max }$ é o valor máximo dos tempos de produção (que assumem valores inteiros). O horizonte de escalonamento propriamente dito, ao qual se referem as decisões de carga das máquinas (ver secção 4.2.3), é o subconjunto de T:

$$
\{0,1,2, \ldots, H\} \text {. }
$$

A necessidade de considerar instantes anteriores a 0 no conjunto $\mathrm{T}$ deve-se a certas restrições do modelo (questão discutida em 4.2.4) e a inclusão do instante $H+1$ deve-se à forma como são tidos em conta os limites dos intervalos de tempo unitários ${ }^{8}$ na definição das variáveis de decisão $X_{p o t}$ e Xfin prt $_{\text {(vd. }}$ secção 4.2.3).

Como pode ser produzida mais do que uma unidade de uma dada peça, os parâmetros $Z_{k}, A_{k}$ e $B_{k}$ são penalidades por unidade de uma peça do molde $k \mathrm{e}$ por unidade de tempo?. Dados $A_{k}$ e $B_{k}$, define-se a seguinte penalidade para um instante $t$ do horizonte de escalonamento:

\footnotetext{
${ }^{8}$ Intervalos de tempo entre instantes consecutivos de $T$ : por exemplo [0,1[ , [1,2[ , [2,3[.

${ }^{9}$ Considerando uma unidade de tempo como um dos intervalos unitários em que o horizonte de escalonamento está dividido.
} 


$$
\psi_{k t}=\left\{\begin{array}{ll}
B_{k}\left(D_{k}-t\right) & t \leq D_{k} \\
A_{k}\left(t-D_{k}\right) & t>D_{k}
\end{array} \quad \forall k \in K, t=0, \ldots, H\right.
$$

É este parâmetro/penalidade que efetivamente surge na função objetivo, sendo obtido pela multiplicação do coeficiente por produzir a unidade da peça atrasada $\left(A_{k}\right)$ ou adiantada $\left(B_{k}\right)$ relativamente à data de entrega $D_{k}$ pelo tempo compreendido entre o instante $t$ e a data de entrega. Assim, a penalidade $\psi_{k t}$ aumenta com o desfasamento entre o instante de conclusão da unidade da peça e a data de entrega.

\subsubsection{Variáveis}
$X_{p o t} \quad$ número de unidades da peça $p$ no buffer da operação $o$ entre os instantes $t-1$ e $t$
Xfin $\quad$ número de unidades da peça $p$ acabadas entre os instantes $t-1$ e $t$
$U_{\text {pomt }} \quad$ número de unidades da peça $p$ carregadas no instante $t$ na máquina $m$, para executar a operação $o$

Todas as variáveis de decisão são inteiras (as peças são produzidas em unidades discretas). A variável $X_{p o t}$ é o número de unidades da peça $p$ que se encontram no buffer que antecede a primeira operação (o) ou nos buffers intermédios que antecedem a operação $o$ na sequência de produção $j$ correspondente, no intervalo de tempo $[t-1, t]^{10}$. Já as unidades da peça $p$ acabadas no intervalo de tempo $[t-1, t$, que se encontram no último buffer, são representadas pela variável $X f_{i n}$. . O número de unidades terminadas no final do horizonte de escalonamento, ou seja, no intervalo $[H, H+1$, é igual a $\operatorname{Xfin}_{p(H+1)}$. A variável $U_{\text {pomt }}$ contabiliza as unidades da peça $p$ carregadas na máquina $m$, no instante $t$, para realizar a operação $o$.

\subsubsection{Modelo OPTMESC}

Tendo em conta as características do problema em estudo, o modelo OPTMESC apresenta a função objetivo e as restrições que se seguem:

\footnotetext{
${ }^{10} \mathrm{Na}$ definição das variáveis $X_{p o t}$ e Xfin $p t$ os intervalos de tempo são fechados à esquerda e abertos à direita.
} 


$$
\begin{aligned}
& \operatorname{Min} \sum_{k \in K} \sum_{j \in J_{k}} \sum_{p \in P_{k j}}\left[N_{k} \cdot\left(Q_{p}-X \operatorname{fin}_{p(H+1)}\right)\right. \\
& \left.+\sum_{t=0}^{H}\left(\psi_{k t \cdot}\left(\operatorname{Xfin}_{p(t+1)}-X \operatorname{fin}_{p t}\right)+\sum_{o \in O_{j} \mid\left\{f_{j}\right\}} Z_{k} \cdot X_{p o t}\right)\right]
\end{aligned}
$$

\section{Sujeito a:}

$$
\begin{gathered}
U_{\text {pomt }}=0 \quad \forall p \in P \forall o \in O_{j}: p \in P_{j} \forall m \in M_{o}, t=-t_{\text {max }}, \ldots,-1 \\
X_{\text {po } 0}=Q_{p} \\
\forall p \in P, o=f_{j}: p \in P_{j} \\
X_{\text {po } 0}=0 \quad \forall p \in P \forall o \in O_{j} \mid\left\{f_{j}\right\}: p \in P_{j} \\
X \text { fin }_{p 0}=0 \\
\forall p \in P
\end{gathered}
$$

$$
X_{p o(t+1)}=X_{p o t}-\sum_{m \in M_{o}} U_{p o m t} \forall p \in P, o=f_{j}: p \in P_{j}, t=0, \ldots, H
$$

$$
X_{p o(t+1)}=X_{p o t}-\sum_{m \in M_{O}} U_{p o m t}+\sum_{m^{\prime} \in M_{o^{\prime}}} U_{p o^{\prime} m^{\prime}\left(t-T_{p o^{\prime} m^{\prime}}\right)}
$$

$$
\forall p \in P \forall \mathrm{o} \in \mathrm{O}_{j} \mid\left\{f_{j}, l_{j}\right\}: p \in P_{j}, \mathrm{t}=0, \ldots, H
$$

$$
\begin{aligned}
& X \operatorname{fin}_{p(t+1)}=X \operatorname{fin}_{p t}+\sum_{m \in M_{o}} U_{\text {pom }\left(t-T_{p o m}\right)} \\
& \quad \forall p \in P, \mathrm{o}=l_{j}: p \in P_{j}, t=0, \ldots, H
\end{aligned}
$$

\footnotetext{
${ }^{11} O$ ' é a operação que antecede a operação $o$ na respetiva sequência de produção (relembre-se que $O_{j}$ é um conjunto de elementos ordenados) e $m$ ' uma das máquinas que pode realizar a operação $o^{\prime}: m^{\prime} \in M_{o^{\prime}}$.
} 


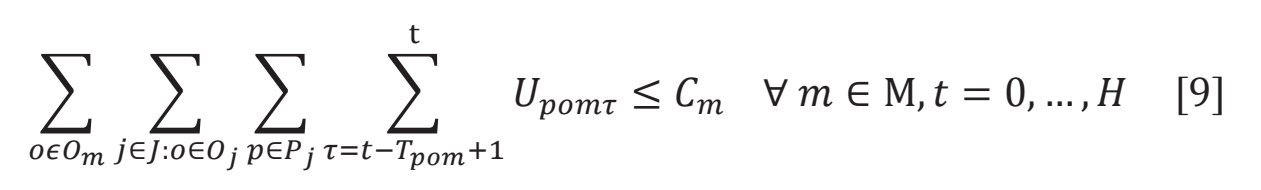

$\sum_{j \in J: o \in \mathrm{O}_{j} \mid\left\{f_{j}\right\}} \sum_{p \in P_{j}} X_{p o t} \leq S_{o} \quad \forall o \in O, t=0, \ldots, H+1$

$X_{\text {pot }}, X$ fin $_{\text {pt }}, U_{\text {pomt }} \in \mathbb{N}_{0}$

A função objetivo [1], a minimizar, é uma soma de penalizações: por existirem peças incompletas no final do horizonte de escalonamento (primeiro termo), pela finalização da produção de peças do molde $k$ antes ou depois da respetiva data de entrega $D_{k}$ (segundo termo) e pelo tempo de espera de peças inacabadas em buffers intermédios (terceiro termo). Relativamente ao segundo termo, a penalidade $\psi_{k t}$ multiplica pelo número de unidades da peça $p$ (do molde $k$ ) terminadas no instante $t$, que é igual à diferença das variáveis $X_{\text {fin }}(t+1)$ e Xfin $n_{p t}$, isto é, do número de unidades no buffer final nos intervalos de tempo $[t, t+1[$ e $[t-1, t[$, respetivamente.

As restrições [2] a [5] traduzem as condições de inicialização. A inexistência de peças carregadas nas máquinas em instantes anteriores ao início do horizonte de escalonamento $(\mathrm{t}=0)$ é imposta por [2] ${ }^{12}$. As restrições [3] garantem que no instante inicial, e no buffer inicial, estão as $Q_{p}$ unidades (idênticas) de cada peça $p$ que se pretende produzir. As restrições [4] e [5] garantem que os buffers intermédios e o buffer final estão vazios no início do horizonte de escalonamento, respetivamente.

As restrições [6], [7] e [8] correspondem aos "balanços de massa" do primeiro buffer, dos buffers intermédios e do buffer final para cada peça, que segue uma dada sequência de produção (j). As restrições [6] calculam o

\footnotetext{
${ }^{12}$ Tal justifica-se porque ao concretizar as restrições [7], [8] e [9] para alguns valores de $t$ do horizonte de escalonamento, surgem variáveis $U$ que se referem a instantes de tempo prévios ao instante inicial e é necessário definir o seu valor. No caso das máquinas estarem ocupadas no início do horizonte de escalonamento, em vez de serem igualadas a zero estas variáveis são igualadas a um valor positivo (ver secção 5.1).
} 
número de unidades da peça $p$ no buffer inicial entre os instantes $t$-1 e $t$ subtraindo ao número de unidades existentes no buffer no intervalo de tempo anterior o número de unidades da peça $p$ que iniciam a sequência de produção $j$ no instante $t$. Estas peças são carregadas nas máquinas que podem realizar a primeira operação da sequência. Desta forma, o somatório das variáveis $U$ estende-se a todas as máquinas de $M_{o}$, sendo $O$ a primeira operação da sequência $j: o=f_{j}$. O buffer é portanto comum a todas as máquinas de $M_{o}$.

As restrições [7] determinam o número de unidades da peça $p$ nos buffers intermédios somando ao número de unidades existentes no intervalo de tempo anterior o número de unidades que na operação anterior da sequência de produção (operação $o^{\prime}$ ) terminaram no instante $t$ e, portanto, foram adicionadas ao buffer da operação o nesse mesmo instante, e subtraindo o número de unidades da peça $p$ que iniciaram a operação $o$ no instante $t$. Por último, as restrições [8] representam a variação do número de unidades da peça $p$ acabadas ao longo do horizonte de escalonamento, que se encontram no buffer final da sequência de produção respetiva: este número é obtido somando às unidades terminadas no intervalo de tempo anterior aquelas que ficaram concluídas no instante $t$, e que portanto iniciaram a última operação no instante $t$ - $T_{\text {pom }}$.

As restrições da capacidade das máquinas [9] são necessárias para contabilizar as peças (ou melhor, unidades de peças) em cada máquina $m$ no instante $t$ do intervalo de escalonamento (e que se mantém no intervalo $[t, t+1$ D). Assim, a soma das variáveis $U$, estendida a todas as operações que podem utilizar a máquina $m$ e às unidades de peças que iniciam aí a operação no instante $t$ ou em instantes anteriores (estando ainda em processamento) ${ }^{13}$ tem de ser menor ou igual à respetiva capacidade, que é o número máximo de unidades que a máquina pode ter simultaneamente em processamento.

As restrições [10] referem-se à capacidade dos buffers. Todas as unidades das peças $p$ têm de ser contabilizadas quando esperam no buffer de cada operação $o$ entre os instantes $t$-1 e $t$. Então a soma das variáveis $X$, estendida a todas as sequências de produção contendo a operação $o$, é menor ou igual à

\footnotetext{
${ }^{13}$ Pelo que nas restrições [9] o somatório no tempo (índice $\tau$ ) se inicia no instante $t-T_{p o m}+1 \mathrm{e}$ termina no instante $t$.
} 
capacidade do buffer desta operação. Estas restrições são escritas para todos os buffers intermédios das sequências (excetua-se o buffer inicial).

Finalmente, as restrições [11] estabelecem a integrabilidade das variáveis de decisão.

\subsubsection{Generalização do modelo: OPTMESC com montagem de peças}

A implementação da operação de montagem no modelo OPTMESC pressupõe a inclusão de uma operação final de montagem em todas as sequências de produção das peças de um dado molde (a montar). A operação de montagem é específica de cada molde, sendo associada uma máquina virtual à sua realização. Esta não corresponde a nenhuma máquina existente no shop floor da fábrica, sendo criada apenas por exigência da formulação matemática, que associa máquinas a operações. Na generalização do modelo efetuada, contempla-se a hipótese de, no conjunto de moldes a escalonar, existirem moldes a montar e moldes sem operação de montagem.

Os novos conjuntos, elementos particulares, restrições e a modificação da função objetivo necessários são os seguintes:

\section{Conjuntos:}

$K_{1}$ moldes com operação de montagem

$K_{2}$ moldes sem operação de montagem

$K=K_{1} \cup K_{2}$

$P_{k} \quad$ peças pertencentes ao molde $\mathrm{k} \quad P_{k} \subset \mathrm{P}$

\section{Elementos particulares de conjuntos:}

$p_{k}^{r} \quad$ peça representativa do molde $k \quad p_{k}^{r} \in P_{k}$

mont $_{k} \quad$ operação de montagem do molde $k \quad$ mont $_{k} \in O$

$m \_$mont $_{k} \quad$ "máquina" onde é realizada a montagem do molde $k$

$$
M_{o}=\left\{m_{-} \text {mont }_{k}\right\} \text { com } o=\text { mont }_{k}
$$


Restrições:

$$
\begin{gathered}
U_{p_{k}^{r} \text { omt }}=U_{\text {pomt }} \\
\forall k \in K_{1} \forall p \in P_{k} \mid\left\{p_{k}^{r}\right\}, o=\text { mont }_{k}, \\
\forall m \in M_{o}, t=0, \ldots, H
\end{gathered}
$$

Função objetivo:

$$
\begin{aligned}
& \operatorname{Min} \sum_{k \in K} \sum_{j \in J_{k}} \sum_{p \in P_{k j}}\left[N_{k} \cdot\left(Q_{p}-X \operatorname{fin}_{p(H+1)}\right)+\sum_{t=0}^{H} \sum_{o \in O_{j} \mid\left\{f_{j}\right\}} Z_{k} \cdot X_{p o t}\right]+ \\
& +\sum_{k \in K_{1}} \sum_{t=0}^{H} \psi_{k t} \cdot\left(X \operatorname{fin}_{p_{k}^{r}(t+1)}-X \operatorname{fin}_{p_{k}^{r} t}\right)+ \\
& +\sum_{k \in K_{2}} \sum_{j \in J_{k}} \sum_{p \in P_{k j}} \sum_{t=0}^{H} \psi_{k t} \cdot\left(X \operatorname{fin}_{p(t+1)}-X \operatorname{fin}_{p t}\right)
\end{aligned}
$$

O conjunto dos moldes é dividido em dois conjuntos disjuntos, $K_{1}$ e $K_{2}$, correspondentes aos moldes com e sem operação de montagem, respetivamente. As peças dos moldes com montagem são todas modeladas individualmente $\left(Q_{p}=1\right)$ e uma das peças do molde (qualquer) é tomada como a peça representativa do mesmo, necessária nas restrições [12] e na função objetivo; designa-se $p_{k}^{r}$.

Assim, as restrições [12] estabelecem a simultaneidade da operação de montagem para todas as peças dos moldes com montagem (aplicando-se apenas aos moldes $k \in K_{1}$ ). Por outro lado, nas restrições [9] de capacidade da "máquina" de montagem do molde $k$ é necessário igualar a capacidade $\left(C_{m}\right)$ ao número de peças do molde.

A função objetivo [1'] difere da anterior apenas no desdobramento da parcela relativa à data de entrega (penalização por finalização antes ou depois da data) para os conjuntos $K_{1}$ e $K_{2}$. No caso de moldes sem montagem $\left(k \in K_{2}\right)$ a penalidade é igual à de [1], afetando todas as peças do molde. Para moldes 
com montagem $\left(k \in K_{1}\right)$ a penalidade apenas se aplica à peça representativa do molde.

\subsection{Exemplo ilustrativo}

Para ilustrar e validar a aplicação do modelo OPTMESC, criou-se um exemplo baseado em dados reais recolhidos na GECO $^{14}$. Este apresenta um conjunto de 8 operações, descritas na tabela 1, que inclui também uma designação abreviada de cada operação. A produção de uma peça pode incluir todas as operações ou apenas algumas, o que depende da sua complexidade. A cada operação (o) está associada uma ou mais máquinas ( $m$ ) que a podem executar, igualmente indicadas na tabela 1 (última coluna). Consideram-se 7 máquinas, algumas das quais executam mais do que uma operação: por exemplo as máquinas $m 1$ e $m 2$ realizam o desbaste (Desb) e o acabamento de estruturas $\left(D N C \_E\right)^{15}$. Cada máquina pode apenas produzir uma peça de cada vez (a sua capacidade é unitária). Já à operação de montagem fez-se corresponder uma "máquina" $m 8$ com capacidade igual a 2 (número de peças que se pretende montar).

Para cada operação existe um buffer ou fila de espera que a antecede tendo-se igualado a respetiva capacidade a 100 unidades. Escolheu-se um valor elevado para esta capacidade porque no escalonamento das operações na empresa não são tidas em conta restrições de espaço (este não é limitativo do escalonamento).

No exemplo existem três peças de um molde a produzir sendo a peça $p 1$ uma bucha, a peça $p 2$ uma cavidade e a peça $p 3$ uma chapa da estrutura. Pretende-se montar as peças p1 e p2 e produzir a peça $p 3$ em separado. A figura 4 ilustra as duas sequências de produção necessárias na implementação do modelo. As operações são representadas por retângulos e os buffers por círculos. Os círculos que se encontram entre as operações correspondem aos buffers intermédios, o primeiro círculo de ambas as sequências corresponde ao buffer inicial e o último círculo de cada sequência corresponde ao buffer final.

\footnotetext{
${ }^{14} \mathrm{Na}$ secção 5 inclui-se um comentário mais pormenorizado sobre o levantamento de dados efetuado na empresa.

15 Designação derivada das máquinas de fresagem DNC que executam a operação.
} 
Existem operações comuns a ambas as sequências de produção e operações que só existem numa das sequências: por exemplo a operação $D N C \_E$ é específica da sequência de produção II. Está definida uma operação de montagem das peças p1 e p2 (na sequência de produção I), pelo que se utilizou o modelo OPTMESC com montagem de peças.

Tabela 1: Operações e máquinas associadas (exemplo ilustrativo).

\begin{tabular}{|c|c|c|}
\hline Operações & Designação no modelo (o) & Máquinas ( $m$ ) \\
\hline Desbaste & Desb & $m 1, m 2$ \\
\hline Furar águas & Furag & $m 3, m 4$ \\
\hline Retificação & Rectif & $m 5$ \\
\hline Acabamento de estruturas & DNC_E & $m 1, m 2$ \\
\hline Acabamento de peças moldantes & DNC_M & $m 6$ \\
\hline Furar fixações e/ou extração & Furfix & $m 3, m 4$ \\
\hline Erosão & Erosao & $m 7$ \\
\hline Montagem & Mont & $m 8$ \\
\hline
\end{tabular}

Os tempos de produção (em horas) são valores inteiros e as mesmas máquinas têm tempos de produção diferentes dependendo do tipo de peça e da sequência de produção. As tabelas 2 e 3 apresentam os valores considerados para estes parâmetros. Na última linha das tabelas figura o tempo total de produção mínimo de cada peça, correspondente à soma dos tempos de produção se forem escolhidas as máquinas mais rápidas (com tempos de produção menores) em operações em que há mais de uma máquina disponível. Os tempos de produção tanto da operação de furar águas como de furar fixações e/ou extração da peça p2 são mais elevados do que os da peça p1 devido ao facto da cavidade ser uma peça mais complexa do que a bucha. A cavidade é a peça por onde se efetua a injeção do material enquanto a bucha é a peça por onde se efetua a extração do molde, operação que requer um mecanismo mais simples do que a injeção. 


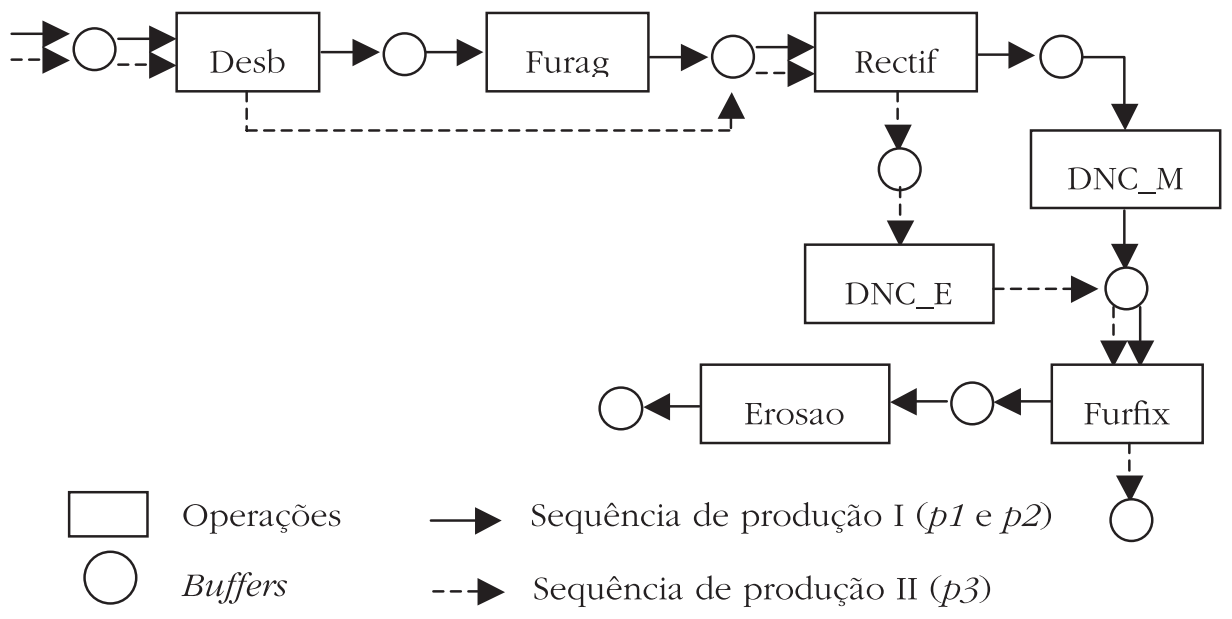

Figura 4: Sequências de produção (exemplo ilustrativo).

Tabela 2: Tempos de produção da sequência de produção I (exemplo ilustrativo).

\begin{tabular}{|c|c|c|c|}
\hline \multirow{2}{*}{ Operação (o) } & \multirow{2}{*}{ Máquinas $(m)$} & \multicolumn{2}{|c|}{ Tempo de produção (horas) } \\
\cline { 2 - 4 } & $m 1$ & 36 & $p 2$ \\
\hline \multirow{2}{*}{ Desb } & $m 2$ & 36 & 36 \\
\cline { 2 - 4 } & $m 3$ & 74 & 36 \\
\hline \multirow{2}{*}{ Furag } & $m 4$ & 72 & 86 \\
\hline \multirow{2}{*}{ Rectif } & $m 5$ & 2 & 84 \\
\hline \multirow{2}{*}{ DNC_M } & $m 6$ & 80 & 2 \\
\hline \multirow{2}{*}{ Furfix } & $m 3$ & 14 & 80 \\
\hline \multirow{2}{*}{ Erosao } & $m 4$ & 12 & 38 \\
\hline Mont & $m 7$ & 48 & 36 \\
\hline \multirow{2}{*}{ Tempo total de produção mínimo (horas) } & 265 & 48 \\
\hline
\end{tabular}


Tabela 3: Tempos de produção da sequência de produção II (exemplo ilustrativo).

\begin{tabular}{|c|c|c|}
\hline \multirow{2}{*}{ Operação (o) } & Máquinas $(m)$ & Tempo de produção (horas) \\
\cline { 2 - 3 } & $m 1$ & $p 3$ \\
\hline \multirow{2}{*}{ Desb } & $m 2$ & 12 \\
\cline { 2 - 3 } & $m 5$ & 12 \\
\hline \multirow{2}{*}{ Rectif } & $m 1$ & 36 \\
\hline \multirow{2}{*}{ DNC_E } & $m 2$ & 36 \\
\cline { 2 - 3 } & $m 3$ & 18 \\
\hline \multirow{2}{*}{ Furfix } & $m 4$ & 16 \\
\cline { 2 - 3 } & & 67 \\
\hline \multirow{2}{*}{ Tempo total de produção mínimo (horas) } & \\
\hline
\end{tabular}

A escolha dos valores dos coeficientes na função objetivo teve como base a atribuição de Gomes (2007): $A_{k}=20, B_{k}=1, Z_{k}=0,1$ e $N_{k}=10^{7}$ (revendo: penalidade por produção após a data de entrega, antes desta, por tempo de espera nos buffers intermédios e pela existência de peças incompletas no final do horizonte de escalonamento). O último coeficiente é muito elevado quando comparado com os restantes para evitar a situação de peças incompletas. De referir que a empresa foi consultada sobre os valores recomendados para estas penalidades mas não foi possível obter uma contrapartida.

A data de entrega das peças p1 e p2 (após montagem) é de 357 horas e a da peça p3 342 horas. Será produzida uma unidade de cada peça, pelo que todas as variáveis de decisão no modelo apenas tomarão valores binários (0 ou 1). O horizonte de escalonamento utilizado foi igual à maior data de entrega: 357 horas dividido em intervalos de uma hora (este horizonte revelou-se suficiente para resolver o problema, cumprindo-se as datas de entrega).

Definidos todos os parâmetros, o modelo OPTMESC (com montagem de peças) foi implementado no sistema de modelação GAMS (versão 23.9.2) e resolvido com o software CPLEX versão 12.3 num computador Intel Core com um processador de 2,20 GHz, 6 GB de RAM e o sistema operativo Windows 7. 
A tabela 4 sumariza os resultados obtidos mostrando as características do modelo (número de variáveis e de restrições), o número de iterações e o tempo computacional necessários para a resolução à otimalidade (a solução ótima é obtida impondo uma margem de erro - relative gap - de 0\% ao correr o CPLEX) e o valor da função objetivo.

Tabela 4: Características numéricas do modelo e resultados (exemplo ilustrativo).

\begin{tabular}{|c|c|c|c|c|}
\hline$N^{\circ}$ de variáveis & $N^{\circ}$ de restrições & $N^{\circ}$ de iterações & Função objetivo & Tempo CPU (s) \\
\hline 19.954 & 16.039 & 3.166 & 5,4 & 4,6 \\
\hline
\end{tabular}

Apresentam-se ainda os resultados detalhados da aplicação do modelo OPTMESC. As tabelas 5 e 6 indicam as sequências de produção para as três peças, com os instantes de início e fim de cada operação bem como a máquina a que esta foi afeta (atribuída). A tabela 7 mostra a ocupação de cada máquina, isto é, a sequência de operações na mesma.

A análise das tabelas 5 e 6 permite concluir que o intervalo de tempo entre inícios sucessivos de operações coincide com os tempos de produção indicados nas tabelas 2 e 3, pelo que não há necessidade das peças esperarem nos buffers. Excetua-se o caso da peça p2 ao passar da operação de Erosão (Erosao) à operação de Montagem (Mont). De facto, para esta peça mediaram 102 horas entre o início das duas operações enquanto o tempo de Erosão era apenas de 48 horas (tabela 2). Assim, após a operação de Erosão a peça esteve no buffer da operação de Montagem durante 54 horas, que se justifica pela necessidade da peça $p 2$ ter de esperar pela $p 1$ para passarem em simultâneo pela operação de Montagem. Em conformidade, a produção de ambas as peças terminou no mesmo instante.

Analisando a tabela 7 verifica-se que não há sobreposição de operações: não se encontra mais do que uma peça em cada máquina num determinado instante, tal como exigido pela restrição de capacidade das máquinas (dado que se considerou uma capacidade unitária). Também se pode verificar que há peças que visitam a mesma máquina mais de uma vez (recirculação de peças). É o caso da peça p3 que é processada na máquina m2 no Desbaste (Desb) e 
volta a ser processada na operação de Acabamento de estruturas (DNC_E); entre estas duas operações foi executada a operação de Retificação (Rectif) da peça na máquina $m 5$ (tabela 6). De notar que na solução devolvida pelo modelo não se fez uso da máquina $m 1$.

Tabela 5: Sequência de produção com montagem das peças $p 1$ e $p 2$.

\begin{tabular}{|c|c|c|c|c|c|c|}
\hline \multirow{2}{*}{$\begin{array}{c}\text { Operação } \\
(o)\end{array}$} & \multicolumn{4}{|c|}{$p 1$} & \multicolumn{2}{|c|}{$p 2$} \\
\cline { 2 - 7 } & $\begin{array}{c}\text { Máquina } \\
(m)\end{array}$ & $\begin{array}{c}\text { Instante de } \\
\text { início }(t)\end{array}$ & $\begin{array}{c}\text { Instante } \\
\text { de fim }(t)\end{array}$ & $\begin{array}{c}\text { Máquina } \\
(m)\end{array}$ & $\begin{array}{c}\text { Instante de } \\
\text { início }(t)\end{array}$ & $\begin{array}{c}\text { Instante } \\
\text { de fim }(t)\end{array}$ \\
\hline Desb & $m 2$ & 90 & 126 & $m 2$ & 0 & 36 \\
\hline Furag & $m 3$ & 126 & 200 & $m 4$ & 36 & 120 \\
\hline Rectif & $m 5$ & 200 & 202 & $m 5$ & 120 & 122 \\
\hline DNC_M & $m 6$ & 202 & 282 & $m 6$ & 122 & 202 \\
\hline Furfix & $m 4$ & 282 & 294 & $m 3$ & 202 & 240 \\
\hline Erosao & $m 7$ & 294 & 342 & $m 7$ & 240 & 288 \\
\hline Mont & $m 8$ & 342 & 357 & $m 8$ & 342 & 357 \\
\hline
\end{tabular}

Tabela 6: Sequência de produção da peça $p 3$.

\begin{tabular}{|c|c|c|c|}
\hline \multirow{2}{*}{ Operação (o) } & \multicolumn{3}{|c|}{$p 3$} \\
\cline { 2 - 4 } & Máquina $(m)$ & Instante de início $(t)$ & Instante de fim $(t)$ \\
\hline Desb & $m 2$ & 273 & 285 \\
\hline Rectif & $m 5$ & 285 & 288 \\
\hline DNC_E & $m 2$ & 288 & 324 \\
\hline Furfix & $m 3$ & 324 & 342 \\
\hline
\end{tabular}

Concluindo com a interpretação do valor ótimo da função objetivo (tabela 4), este resulta do facto da peça p2 ter estado no buffer que antecede a operação de Montagem durante 54 horas, como já mencionado. Não existem peças incompletas no final do horizonte de escalonamento nem se aplica a penalidade por produzir peças antes ou depois da data de entrega (todas as 
peças foram finalizadas exatamente na data de entrega). Sendo assim, o valor da função objetivo é 5,4 $(F O=54 \times 0,1=5,4)$.

Tabela 7: Ocupação das máquinas.

\begin{tabular}{|c|c|c|c|c|}
\hline Máquina $(m)$ & Operação (o) & $\operatorname{Peça~}(p)$ & Instante de início & Instante de fim \\
\hline \multirow{4}{*}{$m 2$} & Desb & $p 2$ & 0 & 36 \\
\hline & Desb & $p 1$ & 90 & 126 \\
\hline & Desb & $p 3$ & 273 & 285 \\
\hline & DNC_E & $p 3$ & 288 & 324 \\
\hline \multirow{3}{*}{$m 3$} & Furag & $p 1$ & 126 & 200 \\
\hline & Furfix & $p 2$ & 202 & 240 \\
\hline & Furfix & $p 3$ & 324 & 342 \\
\hline \multirow{2}{*}{$m 4$} & Furag & $p 2$ & 36 & 120 \\
\hline & Furfix & $p 1$ & 282 & 294 \\
\hline \multirow{3}{*}{$m 5$} & Rectif & $p 2$ & 120 & 122 \\
\hline & Rectif & $p 1$ & 200 & 202 \\
\hline & Rectif & p3 & 285 & 288 \\
\hline \multirow{2}{*}{$m 6$} & DNC_M & $p 2$ & 122 & 202 \\
\hline & DNC_M & $p 1$ & 202 & 282 \\
\hline \multirow{2}{*}{$m 7$} & Erosao & $p 2$ & 240 & 288 \\
\hline & Erosao & $p 1$ & 294 & 342 \\
\hline \multirow{2}{*}{$m 8$} & Mont & $p 1$ & 342 & 357 \\
\hline & Mont & $p 2$ & 342 & 357 \\
\hline
\end{tabular}

\section{Caso de estudo}

Nesta secção descreve-se em primeiro lugar a aplicação do modelo OPTMESC à determinação de um plano de produção da empresa. Foram utilizados os dados de um plano real obtido pelo líder de grupo (LG), comparando-se a solução do modelo com este plano (solução manual). Para tal, foi necessário proceder a um levantamento das características do parque das máquinas da GECO (para cada máquina, as operações que podem ser 
realizadas na mesma e as dimensões máximas nos eixos $\mathrm{X}, \mathrm{Y}$ e $\mathrm{Z}$ das peças que suporta), bem como um levantamento das operações e respetivas durações (tempos de produção) de todas as peças envolvidas no plano de produção. A informação compilada está descrita na dissertação de mestrado de Virgílio (2011). Na segunda parte, apresenta-se uma análise pós-otimização aos coeficientes da função objetivo, às datas de entrega das encomendas e à duração do horizonte de escalonamento utilizado, os parâmetros mais relevantes do modelo.

\subsection{Aplicação a um plano de produção da empresa}

O plano de produção selecionado consiste em 42 peças pertencentes a 6 moldes diferentes e envolve a afetação de operações a 9 máquinas (de capacidade unitária). A tabela 8 descreve estas operações e a divisão que foi necessário efetuar pelo facto de certas peças só poderem ser carregadas em determinadas máquinas. São as operações resultantes da divisão referida que constituem o conjunto $O$ de operações no modelo (vd. secção 4.2.1), indicando-se na tabela 8 as máquinas que lhes estão associadas. Por exemplo, a operação de desbaste foi dividida em três operações (Desb1, Desb2, Desb3) devido às máquinas disponíveis. A máquina $m 1$ pode efetuar qualquer destas operações, pois suporta peças de maior dimensão e portanto pode também desbastar peças de menor dimensão. Contudo, a máquina m2 apenas pode efetuar a operação Desb1 pois só suporta peças de dimensão reduzida.

Após a definição das operações de uma forma utilizável no modelo OPTMESC, definiram-se, com base na consulta do plano do LG, 12 sequências de produção para as peças envolvendo no total 52 operações. Para uma mesma máquina os tempos de produção diferem consoante a operação e a peça. O conjunto das sequências de produção e os tempos respetivos estão descritos em Virgílio (2011). De referir que, ao determinar o plano de produção, o LG recorre à sua experiência para definir as operações (que variam de acordo com o tipo de peça) e estimar os respetivos tempos de fabrico ${ }^{16}$. Tal

\footnotetext{
${ }^{16}$ Os LG possuem por isso um conhecimento prático das várias etapas do processo indispensável a este "pré-processamento" das operações para a determinação do plano de produção.
} 
como no exemplo ilustrativo (e pelas mesmas razões) optou-se por igualar a capacidade dos buffers das operações a 100 unidades.

Tabela 8: Operações e máquinas associadas (plano de produção).

\begin{tabular}{|c|c|c|}
\hline \multirow{2}{*}{ Operação } & Operação no modelo (o) & Máquinas $(m)$ \\
\hline \multirow{2}{*}{ Desbaste } & Desb1 & $m 1, m 2, m 7, m 8$ \\
\cline { 2 - 3 } & Desb2 & $m 1, m 7$ \\
\cline { 2 - 3 } & Desb3 & $m 1$ \\
\hline \multirow{2}{*}{ Furar águas } & Furag & $m 9$ \\
\hline \multirow{2}{*}{ Acabamento de estruturas } & DNC_E1 & $m 1, m 7$ \\
\cline { 2 - 3 } & DNC_E2 & $m 1$ \\
\hline \multirow{3}{*}{ Acabamento de peças moldantes } & DNC_M1 & $m 3, m 4, m 5, m 6$ \\
\cline { 2 - 3 } & DNC_M2 & $m 3, m 4$ \\
\cline { 2 - 3 } & DNC_M3 & $m 4$ \\
\hline \multirow{2}{*}{ Furar fixações e/ou extração } & Furfix & $m 9$ \\
\hline
\end{tabular}

Considerou-se a forma do modelo OPTMESC sem montagem de peças, pois esta operação não foi tida em conta pelo LG no plano de produção. Assim, todas as peças pertencentes a um dado molde surgem na função objetivo com a mesma data de entrega. As peças e datas de entrega figuram na tabela 9; cada uma das linhas corresponde a um molde (são 6 no total). É produzida uma unidade de cada peça $\left(Q_{p}=1\right)$ e as penalidades na função objetivo são idênticas às do exemplo ilustrativo.

O plano de produção do LG corresponde a um intervalo de tempo de 51 dias, isto é, 2 meses e 9 dias de laboração da fábrica (não contando fins de semana). Constatou-se que os tempos de produção expressos neste plano são múltiplos inteiros de 6 horas, período que corresponde a meio dia de laboração (um dia tem 12 horas de laboração). Assim, na grelha temporal utilizada no modelo OPTMESC a unidade de tempo corresponde a meio dia, estando as datas de entrega na tabela 9 expressas nessa unidade de tempo (meios-dias). 
Verificou-se existirem no plano do LG várias máquinas ocupadas no início do horizonte de escalonamento (todas com exceção das máquinas m1 e m3). Esta pré-ocupação das máquinas foi considerada no modelo OPTMESC modificando as restrições de inicialização [2] de forma a garantir que as máquinas não estejam disponíveis no início do horizonte de escalonamento. As variáveis de decisão correspondem a operações que foram iniciadas e terminadas (no horizonte de escalonamento) no plano do LG.

Estudaram-se duas situações distintas na determinação do plano de produção, designadas plano A1 e plano B1. No primeiro são apenas tidas em conta as peças produzidas internamente na GECO no plano do LG. No segundo, além das peças do plano A1 incluíram-se peças que foram subcontratadas no plano do LG. Na verdade, desse plano constavam 56 peças das quais 42 foram produzidas na empresa (as peças que integraram o plano A1) e 14 foram subcontratadas por receio de que a capacidade das máquinas fosse insuficiente para o cumprimento das datas de entrega.

Para verificar se seria possível produzir mais peças internamente face ao plano do LG, introduziu-se uma peça de cada vez no conjunto de dados do plano A1 e resolveu-se de novo o modelo OPTMESC, repetindo-se o procedimento até deixar de ser possível finalizar todas as peças no horizonte de escalonamento estipulado. A estratégia utilizada na escolha das peças consistiu em dar prioridade às peças principais do molde (cavidades e buchas). Desta forma verificou-se ser viável produzir mais 7 das 14 peças subcontratadas, num total de 49 peças escalonadas. A introdução destas peças requer o acréscimo de novas sequências de produção para 5 peças, sendo utilizadas para as restantes 2 peças sequências de produção já definidas para o plano A1. De referir ainda que estas 7 peças pertencem aos 6 moldes do plano A1. As peças adicionais deste novo plano de produção (plano B1) estão discriminadas entre parêntesis na tabela 9.

Para a implementação e resolução do modelo OPTMESC utilizaram-se as mesmas ferramentas computacionais descritas em 4.3. O horizonte de escalonamento é de 105 meios-dias (o múltiplo de 5 imediatamente superior à maior data de entrega na tabela 9). As características dos modelos de programação linear inteira obtidos e os resultados da sua resolução são 
apresentados nas tabelas 10A e 10B, para uma margem de erro de 0\%. De referir que usando margens de erro de 5\% e 10\% se obteve a mesma solução (com os mesmos valores da função objetivo e das variáveis de decisão) em tempos computacionais semelhantes. Quanto às medidas de desempenho de ambas as soluções (planos de produção), além do valor da função objetivo indicam-se nas tabelas 10A e $10 \mathrm{~B}$ as componentes desta função antes de multiplicadas pelos respetivos coeficientes: o tempo total de espera nos buffers intermédios e da produção de peças antes e após a data de entrega.

Tabela 9: Dados das peças para 6 moldes (plano A1 + peças adicionais consideradas no plano B1).

\begin{tabular}{|c|c|}
\hline Peças $(p)$ & Data de entrega $\left(D_{k}\right)$ \\
\hline$p 1, p 2, p 3, p 4, p 5, p 6, p 7, p 8$ & 26 \\
\hline$p 9, p 10, p 11, p 12, p 13, p 14, p 15$ & 80 \\
\hline$p 16, p 17, p 18, p 19, p 20, p 21+(p 43, p 44, p 45, p 47-p$ lano B1) & 76 \\
\hline$p 22, p 23, p 24, p 25, p 26, p 27, p 28, p 29$ & 86 \\
\hline$p 30, p 31, p 32, p 33, p 34, p 35, p 36+(p 49-$ plano B1) & 102 \\
\hline$p 37, p 38, p 39, p 40, p 41, p 42+(p 46, p 48-$ plano B1) & 102 \\
\hline
\end{tabular}

Tabela 10A: Caraterísticas numéricas do modelo e resultados para os planos de produção A1 e B1.

\begin{tabular}{|c|c|c|c|c|c|}
\hline \multirow{2}{*}{ Plano } & \multirow{2}{*}{$\mathrm{N}^{\circ}$ de peças } & $\begin{array}{c}\mathrm{N}^{\circ} \mathrm{de} \\
\text { variáveis }\end{array}$ & $\begin{array}{c}\mathrm{N}^{\circ} \mathrm{de} \\
\text { restrições }\end{array}$ & $\begin{array}{c}\mathrm{N}^{\circ} \text { de } \\
\text { iterações }\end{array}$ & $\mathrm{N}^{\circ}$ de nós \\
\hline $\mathrm{A} 1$ & 42 & 30.401 & 18.164 & 4.992 & 786 \\
\hline $\mathrm{B} 1$ & 49 & 34.302 & 20.490 & 16.983 & 6 \\
\hline
\end{tabular}

Tabela 10B: Caraterísticas numéricas do modelo e resultados para os planos de produção A1 e B1.

\begin{tabular}{|c|c|c|c|c|c|}
\hline Plano & $\begin{array}{c}\text { Função } \\
\text { objetivo }\end{array}$ & $\begin{array}{c}\text { Tempo } \\
\text { CPU (s) }\end{array}$ & $\begin{array}{c}\text { Tempo nos } \\
\text { buffers }\end{array}$ & $\begin{array}{c}\text { Tempo } \\
\text { antes da } \\
\text { data }\end{array}$ & $\begin{array}{c}\text { Tempo } \\
\text { após a data }\end{array}$ \\
\hline A1 & 384,60 & 4,62 & 186 & 366 & 0 \\
\hline B1 & 485,40 & 3,29 & 234 & 462 & 0 \\
\hline
\end{tabular}


Analisando os resultados, é de salientar que em ambos os casos o modelo OPTMESC foi resolvido à otimalidade em menos de 5 segundos. Não existem peças incompletas no final do horizonte de escalonamento nem peças terminadas depois da data de entrega em ambos os planos, sendo o valor da função objetivo superior para o plano B1 devido ao aumento do tempo total de peças à espera nos buffers e produzidas antes da data. De referir ainda que o tempo de CPU foi inferior no caso do plano B1, apesar da dimensão do modelo ser superior (maior número de variáveis e de restrições). Com efeito, o número de nós analisados na pesquisa branch-and-bound foi consideravelmente inferior para o plano B1, justificando um menor tempo de cálculo. Para comparar o desempenho do modelo com a solução manual, em termos do tempo de cálculo, inquiriu-se o LG: este, dada a experiência que acumulou, demora em média uma hora a planear um conjunto de peças semelhante. O uso do modelo OPTMESC poderá assim reduzir muito significativamente o tempo despendido na determinação de um plano de produção na GECO.

Na figura 5 efetua-se uma comparação entre os planos do LG e os planos A1 e B1 no que respeita às taxas de ocupação das máquinas. A taxa média de ocupação das máquinas no plano do LG e no plano A1 é de 71\% mas o desvio padrão difere, sendo de $24 \%$ no primeiro caso e $19 \%$ no segundo. Constata-se portanto que o modelo OPTMESC produziu uma solução mais uniforme do ponto de vista da afetação das operações às máquinas. Quanto ao plano B1, apresenta uma taxa média de ocupação das máquinas superior (79\%) devido à introdução de mais peças mas o desvio padrão, de 20\%, mantém-se muito próximo do observado no plano A1.

Em anexo inclui-se a carta de Gantt correspondente ao plano B1, desenhada com recurso ao software Microsoft Project, com dois objetivos: permitir a visualização da solução produzida pelo modelo e ilustrar a representação dos planos de produção comummente usada na GECO.

\subsection{Análise pós-otimização}

Os coeficientes, ou penalidades, que figuram na função objetivo têm uma influência determinante sobre as características da solução obtida. Por esse 
motivo averiguou-se junto do LG quais os valores recomendados para as penalidades, mas dada a falta de familiaridade deste com o modelo OPTMESC não foram sugeridos outros valores. Assim, torna-se importante uma análise dos coeficientes da função objetivo do modelo.
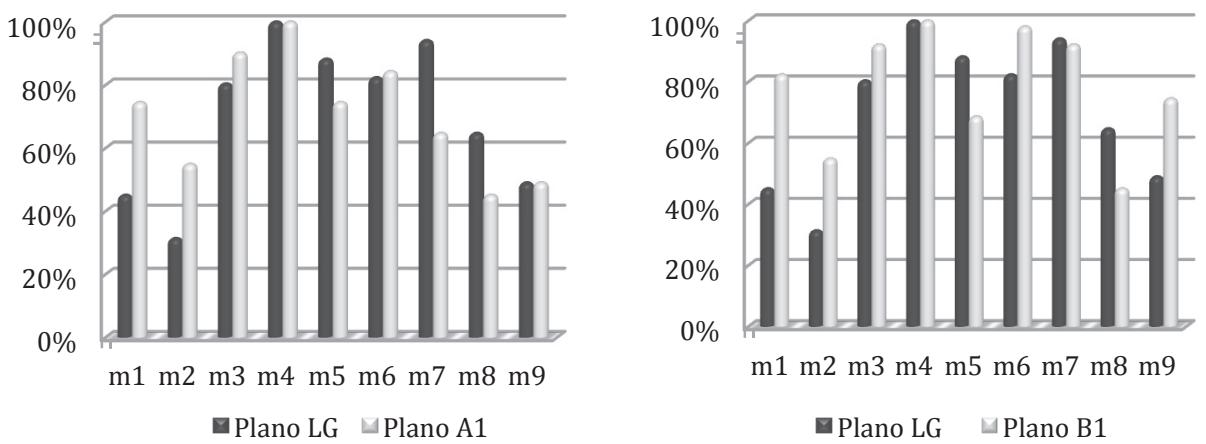

Figura 5: Ocupação das máquinas nos planos do LG, A1 e B1.

Partindo do plano com o maior número de peças (solução B1) variaram-se as penalidades do tempo de espera nos buffers $\left(Z_{k}\right)$ e do tempo total de produção antes $\left(\mathrm{B}_{k}\right)$ e após a data de entrega $\left(\mathrm{A}_{k}\right)$, observando-se o impacto sobre a solução obtida. Não se variou a penalidade $\mathrm{N}_{\mathrm{k}}$ pois esta só tem efeito na função objetivo quando não é possível finalizar todas as peças no horizonte de escalonamento, o que não é o caso para o horizonte de escalonamento utilizado (105 meios-dias). Os resultados figuram nas tabelas $11 \mathrm{~A}$ e 11B. A solução B2 foi obtida com penalidades iguais para as três medidas de desempenho (e iguais a 1) enquanto as soluções B3 e B4 correspondem a dar maior importância a duas das componentes (penalidades iguais a 100) mantendo a outra penalidade igual a 1. Todas as soluções são ótimas (margem de erro de $0 \%)$.

De notar, em primeiro lugar, que os valores da função objetivo das quatro soluções não são comparáveis devido aos coeficientes serem diferentes; é relevante, sim, comparar os valores das medidas de desempenho tempo nos buffers, tempo de produção antes e após a data de entrega. Nas soluções B1 e B3 não são produzidas peças após as datas de entrega, ao contrário das soluções B2 e B4. A solução B3 é diferente da B1 sobretudo no tempo de 
espera nos buffers, bastante reduzido (apenas 8 meios-dias no total) devido à penalidade respetiva ter aumentado face à usada em B1. A solução B1 é aquela com tempo de espera nos buffers mais elevado, B3 a que tem o pior valor de tempo de produção antes da data e B4 a que mais ultrapassa as datas de entrega, em consonância com uma menor importância relativa de cada uma destas medidas de desempenho na função objetivo (respetivamente, os valores de $\mathrm{Z}_{k}, \mathrm{~B}_{k}$ e $\mathrm{A}_{k}$ ). Na solução $\mathrm{B} 2$, com penalidades iguais para as três medidas de desempenho, obtiveram-se valores intermédios das mesmas face às restantes soluções da tabela. Quanto ao tempo de computação, de referir que as soluções B1, B3 e B4 demoraram alguns segundos a ser calculadas enquanto o tempo requerido para a solução B2 foi uma ordem de grandeza superior (cerca de 30 segundos). De facto, o número de nós da árvore de procura (processo branch-and-bound) analisados foi muito superior para esta solução: cerca de 1000 contra um máximo de 25 na solução B3.

Partindo da solução B1 estudou-se ainda o impacto sobre o desempenho da solução ótima de aproximar ("compactar") as datas de entrega. Não se variou a data de entrega do conjunto de peças do primeiro molde (26 meios-dias) mas as restantes foram diminuídas, em simultâneo, 10, 20, 30 e 40 meios-dias como se mostra na tabela 12. Manteve-se o horizonte de escalonamento de 105 meios-dias e a função objetivo da solução B1 (penalidades $A_{k}=20, B_{k}=1$ e $\left.Z_{k}=0,1\right)$, sendo os resultados desta análise apresentados na tabela 13 .

A tabela 13 mostra que à medida que as datas de entrega são compactadas a função objetivo se degrada, aumentando de valor, e o tempo de CPU necessário para resolver o modelo à otimalidade cresce. Excetua-se a passagem da solução B1 à B5, em que o tempo de cálculo da segunda é ligeiramente inferior ao da primeira. O aumento do valor da função objetivo deve-se ao aumento do tempo de produção após a data, embora o tempo de espera nos buffers diminua tal como o tempo de produção antes da data.

As soluções B1 a B7 apresentam tempos de resolução que não ultrapassam 40 segundos enquanto para a solução B8 este foi de 656 segundos (cerca de 11 minutos). O número de nós analisados na árvore de procura de facto aproxima-se de 20.000, significativamente superior aos das soluções anteriores. 
Para esta solução (B8) efetuou-se por último a experiência de encurtar o horizonte de escalonamento. Os resultados figuram nas tabelas 14A e 14B.

Tabela 11A: Análise às penalidades na função objetivo.

\begin{tabular}{|c|c|c|c|c|c|c|}
\hline Solução & \multicolumn{3}{|c|}{ B1 } & \multicolumn{3}{|c|}{ B2 } \\
\hline Penalidades & $A_{k}=20$ & $\mathrm{~B}_{\mathrm{k}}=1$ & $\mathrm{Z}_{\mathrm{k}}=0,1$ & $\mathrm{~A}_{\mathrm{k}}=1$ & $\mathrm{~B}_{\mathrm{k}}=1$ & $Z_{k}=1$ \\
\hline $\mathrm{N}^{\circ}$ de variáveis & \multicolumn{6}{|c|}{34.302} \\
\hline $\mathrm{N}^{\circ}$ de restrições & \multicolumn{6}{|c|}{20.490} \\
\hline $\mathrm{N}^{\circ}$ de iterações & \multicolumn{3}{|c|}{16.983} & \multicolumn{3}{|c|}{144.854} \\
\hline $\mathrm{N}^{\circ}$ de nós & \multicolumn{3}{|c|}{6} & \multicolumn{3}{|c|}{998} \\
\hline Tempo CPU (s) & \multicolumn{3}{|c|}{3,32} & \multicolumn{3}{|c|}{29,59} \\
\hline Função objetivo & \multicolumn{3}{|c|}{485,40} & \multicolumn{3}{|c|}{570} \\
\hline Margem de erro & \multicolumn{3}{|c|}{0} & \multicolumn{3}{|c|}{0} \\
\hline Tempo nos buffers & \multicolumn{3}{|c|}{234} & \multicolumn{3}{|c|}{57} \\
\hline Tempo antes da data & \multicolumn{3}{|c|}{462} & \multicolumn{3}{|c|}{472} \\
\hline Tempo após a data & \multicolumn{3}{|c|}{0} & \multicolumn{3}{|c|}{41} \\
\hline
\end{tabular}

Tabela 11B: Análise às penalidades na função objetivo.

\begin{tabular}{|c|c|c|c|c|c|c|}
\hline Solução & \multicolumn{3}{|c|}{ B3 } & \multicolumn{3}{|c|}{ B4 } \\
\hline Penalidades & $\mathrm{A}_{\mathrm{k}}=100$ & $\mathrm{~B}_{\mathrm{k}}=1$ & $\mathrm{Z}_{\mathrm{k}}=100$ & $\mathrm{~A}_{\mathrm{k}}=1$ & $\mathrm{~B}_{\mathrm{k}}=100$ & $Z_{k}=100$ \\
\hline $\mathrm{N}^{\circ}$ de variáveis & \multicolumn{6}{|c|}{34.302} \\
\hline $\mathrm{N}^{\circ}$ de restrições & \multicolumn{6}{|c|}{20.490} \\
\hline $\mathrm{N}^{\circ}$ de iterações & \multicolumn{3}{|c|}{15.110} & \multicolumn{3}{|c|}{21.153} \\
\hline $\mathrm{N}^{\circ}$ de nós & \multicolumn{3}{|c|}{25} & \multicolumn{3}{|c|}{3} \\
\hline Tempo CPU (s) & \multicolumn{3}{|c|}{4,77} & \multicolumn{3}{|c|}{5,51} \\
\hline Função objetivo & \multicolumn{3}{|c|}{1.422} & \multicolumn{3}{|c|}{50.106} \\
\hline Margem de erro & \multicolumn{3}{|c|}{0} & \multicolumn{3}{|c|}{0} \\
\hline Tempo nos buffers & \multicolumn{3}{|c|}{8} & \multicolumn{3}{|c|}{34} \\
\hline Tempo antes da data & \multicolumn{3}{|c|}{622} & \multicolumn{3}{|c|}{466} \\
\hline Tempo após a data & \multicolumn{3}{|c|}{0} & \multicolumn{3}{|c|}{106} \\
\hline
\end{tabular}


Tabela 12: Variação das datas de entrega face à solução B1.

\begin{tabular}{|c|c|c|c|c|c|}
\hline \multirow{3}{*}{ Peças $(p)$} & \multicolumn{5}{|c|}{$\begin{array}{c}\text { Variação das datas de entrega } \\
\qquad\left(D_{k}\right)\end{array}$} \\
\hline & 0 & -10 & -20 & -30 & -40 \\
\hline & Sol. B1 & Sol. B5 & Sol. B6 & Sol. B7 & Sol. B8 \\
\hline$p 1, p 2, p 3, p 4, p 5, p 6, p 7, p 8$ & 26 & 26 & 26 & 26 & 26 \\
\hline$p 9, p 10, p 11, p 12, p 13, p 14, p 15$ & 80 & 70 & 60 & 50 & 40 \\
\hline $\begin{array}{l}\text { p16, p17, p18, p19, p20, p21 + (p43, p44, p45, p47- } \\
\text { plano B1) }\end{array}$ & 76 & 66 & 56 & 46 & 36 \\
\hline$p 22, p 23, p 24, p 25, p 26, p 27, p 28, p 29$ & 86 & 76 & 66 & 56 & 46 \\
\hline$p 30, p 31, p 32, p 33, p 34, p 35, p 36+(p 49-$ plano B1) & 102 & 92 & 82 & 72 & 62 \\
\hline p37, p38, p39, p40, p41, p42+(p46, p48 - plano B1) & 102 & 92 & 82 & 72 & 62 \\
\hline
\end{tabular}

Tabela 13: Análise da variação das datas de entrega.

\begin{tabular}{|l|c|c|c|c|c|}
\hline Solução & B1 & B5 & B6 & B7 & B8 \\
\hline Variação das datas & 0 & -10 & -20 & -30 & -40 \\
\hline $\mathrm{N}^{\circ}$ de variáveis & \multicolumn{5}{|c|}{34.302} \\
\hline $\mathrm{N}^{\circ}$ de restrições & \multicolumn{5}{|c|}{20.490} \\
\hline $\mathrm{N}^{\circ}$ de iterações & 16.983 & 17.433 & 51.012 & 244.216 & 2.028 .778 \\
\hline $\mathrm{N}^{\circ}$ de nós & 6 & 0 & 110 & 2.148 & 19.123 \\
\hline Tempo CPU (s) & 3,32 & 2,01 & 10,51 & 39,38 & 655,59 \\
\hline Função objetivo & 485,40 & 566,20 & $1.832,20$ & $3.980,60$ & $7.193,00$ \\
\hline Margem de erro & 0 & 0 & 0 & 0 & 0 \\
\hline Tempo nos buffers & 234 & 222 & 82 & 56 & 30 \\
\hline Tempo antes da data & 462 & 504 & 464 & 375 & 290 \\
\hline Tempo após a data & 0 & 2 & 68 & 180 & 345 \\
\hline
\end{tabular}

Verifica-se que para horizontes de escalonamento de 104 a 94 meios-dias as soluções não variam, em termos do valor da função objetivo e das medidas de desempenho das três últimas colunas da tabela 14A, face à solução B8, obtida com um horizonte de escalonamento de 105 meios-dias. 
Tabela 14A: Análise da variação do horizonte de escalonamento.

\begin{tabular}{|l|c|c|c|c|}
\hline Solução & B8 & B9 & B10 & B11 \\
\hline Horizonte temporal & 105 & 104 & 94 & 93 \\
\hline $\mathrm{N}^{\circ}$ de variáveis & 34.302 & 34.038 & 31.398 & 31.398 \\
\hline $\mathrm{N}^{\circ}$ de restrições & 20.490 & 20.367 & 20.354 & 19.137 \\
\hline $\mathrm{N}^{\circ}$ de iterações & 2.028 .778 & 1.097 .998 & 996.756 & 716.312 \\
\hline $\mathrm{N}^{\circ}$ de nós & 19.123 & 13.458 & 13.352 & 6.571 \\
\hline Tempo CPU (s) & 655,59 & 632,41 & 565,32 & 137,06 \\
\hline Função objetivo & $7.193,00$ & $7.193,00$ & $7.193,00$ & $7.745,40$ \\
\hline Margem de erro & 0 & 0 & 0 & 0 \\
\hline Tempo nos buffers & 30 & 30 & 30 & 84 \\
\hline Tempo antes da data & 290 & 290 & 290 & 277 \\
\hline Tempo após a data & 345 & 345 & 345 & 373 \\
\hline
\end{tabular}

Tabela 14B: Análise da variação do horizonte de escalonamento.

\begin{tabular}{|l|c|c|c|}
\hline Solução & B12 & B13 & B14 \\
\hline Horizonte temporal & 92 & 92 & 92 \\
\hline$N^{\circ}$ de variáveis & 30.870 & 30.870 & 30.870 \\
\hline$N^{\circ}$ de restrições & 18.891 & 18.891 & 18.891 \\
\hline$N^{\circ}$ de iterações & 3.680 .171 & 36.155 & 36.155 \\
\hline$N^{\circ}$ de nós & 36.088 & 117 & 117 \\
\hline Tempo CPU (s) & $1.272,33$ & 303,67 & 303,63 \\
\hline Função objetivo & $10.006 .262,30$ & $10.006 .301,10$ & $10.006 .301,10$ \\
\hline Margem de erro & 0 & $5 \%$ & $10 \%$ \\
\hline Tempo nos buffers & 23 & 61 & 61 \\
\hline Tempo antes da data & 280 & 275 & 275 \\
\hline Tempo após a data & 299 & 301 & 301 \\
\hline
\end{tabular}

Indicam-se na tabela 14A as soluções para os dois valores do comprimento do horizonte de escalonamento referidos (104 e 94 meios-dias), designadas B9 
e B10. Apenas para um horizonte de escalonamento de 93 meios-dias se obtém uma solução com um valor da função objetivo diferente (superior) ao da solução B8: trata-se da solução B11 na tabela. Comparando com a solução B8, observa-se que o aumento do valor ótimo da função objetivo resulta do aumento do tempo de produção após a data e do tempo de espera nos buffers, embora o tempo de produção antes da data tenha diminuído. De referir que esta nova solução (B11) foi calculada num tempo de CPU bastante mais curto (137 segundos contra 656, isto é, cerca de 2 minutos contra 11), em conformidade com um número de nós analisados inferior. Ao diminuir o horizonte de escalonamento para 92 meios-dias deixa de ser possível produzir todas as peças (solução B12, tabela 14B): há uma peça que não foi terminada, razão pela qual o valor da função objetivo aumentou muito $\left(N_{k}=10^{7}\right)$. O modelo foi agora mais difícil de resolver: o tempo de CPU para o cálculo da solução ótima (margem de erro nula) subiu para 1272 segundos (cerca de 21 minutos), tendo o número de nós analisados quase duplicado face a B8. De notar, todavia, que no caso deste horizonte de escalonamento (92 meios-dias), se impusermos uma margem de erro superior a zero ao correr o modelo é possível obter uma boa solução em tempos de CPU significativamente inferiores. De facto, a tabela 14B mostra que com margens de erro de 5\% ou de 10\%, o modelo devolve uma solução em 304 segundos (cerca de 5 minutos), idêntica nos dois casos em termos da função objetivo e medidas de desempenho (soluções B13 e B14, respetivamente).

Conclui-se assim que a influência do horizonte de escalonamento escolhido ao resolver o modelo é determinante, tanto do ponto de vista da qualidade da solução como do tempo de computação. A tolerância face à proximidade do ótimo (margem de erro) tem igualmente um impacto importante. Com o modelo OPTMESC o decisor poderá testar diferentes valores para estes parâmetros e escolher uma de entre as várias soluções geradas.

\section{Conclusões e trabalho futuro}

Este trabalho propõe um modelo de programação linear inteira, OPTMESC, para resolver o problema do escalonamento da produção no setor dos moldes. Este modelo, de tempo discreto, foi aplicado a dados reais disponibilizados 
pela empresa GECO, determinando-se um plano (para um período de 2 meses e 9 dias) envolvendo a produção de várias peças de diferentes moldes. Com recurso aos modernos sistemas de implementação e resolução de modelos de programação matemática (linguagem GAMS e solver CPLEX, no caso presente) foram obtidas as soluções ótimas para duas instâncias do problema (planos A1 e B1) numa questão de segundos. Numa comparação com o plano do diretor de produção da empresa, mostrou-se que com a capacidade disponível das máquinas é possível escalonar um número significativo de peças adicionais cuja produção foi subcontratada no referido plano. Este é um resultado relevante pois a redução da subcontratação de peças reduz a incerteza associada à sua qualidade e ao cumprimento das datas de entrega dos moldes.

A análise pós-otimização realizada ilustra o tipo de testes que o decisor pode efetuar com o modelo OPTMESC de forma a escolher a solução (plano de produção) que julgue globalmente mais adequada, por exemplo atribuindo diferentes penalidades às medidas de desempenho na função objetivo. Mostrou-se ainda como o modelo pode ser utilizado para testar a possibilidade de tentar cumprir diferentes datas de entrega, dada a capacidade disponível das máquinas, e ilustrou-se o impacto de variações no horizonte de escalonamento e margem de erro sobre as soluções geradas.

A consulta do responsável de produção sobre os coeficientes (penalidades) utilizados no modelo OPTMESC merece uma reflexão. Não foi possível obter uma crítica ou uma contrapartida para os valores utilizados, tendo apenas sido referido que há cinco anos que a GECO não entrega uma encomenda atrasada e pretende manter essa imagem no mercado. Com efeito, um problema que surge frequentemente ao tentar aplicar a Investigação Operacional em organizações é a dificuldade em formular o objetivo a atingir, que num modelo de programação linear se consubstancia na função objetivo. Há portanto necessidade de trabalhar muito de perto com as pessoas responsáveis na empresa, integrando-as nas fases de estruturação do problema e definição dos objetivos a atingir. Este aspeto foi levado a cabo ao longo deste caso de estudo e apesar de não se terem conseguido todos os dados requeridos (nomeadamente os valores das penalidades na função objetivo), o resultado do trabalho contribuiu positivamente para uma análise mais estruturada do 
problema de escalonamento, para além da informação positiva sobre uma forma de melhorar o planeamento da empresa.

Os tempos computacionais obtidos são compatíveis com uma periodicidade semanal de resolução do problema (obtenção de novos escalonamentos), que é a situação habitual na empresa. O modelo mostra-se portanto adequado à inclusão num sistema de apoio à decisão (SAD) para o escalonamento na indústria de moldes, na qual o problema é ainda comummente resolvido sem recurso a algoritmos implementados em computador. De facto, o diretor de produção da GECO viu com muito interesse o desenvolvimento deste projeto e os resultados obtidos. Porém, a operacionalização de tal ferramenta SAD vai requerer a criação de uma interface amigável, interativa e flexível com o utilizador, que permita nomeadamente visualizar o plano de carga das máquinas (carta de Gantt) diretamente a partir dos resultados do modelo. Conceber esta interface é uma das direções de trabalho futuro.

As outras direções de trabalho têm a ver com generalizações do modelo OPTMESC. Em primeiro lugar, surge a generalização que contemple a decisão sobre as peças a subcontratar em caso de falta de capacidade interna. Neste trabalho o procedimento usado na seleção de peças para obtenção do plano B1 foi uma heurística simples, e será importante estudar a otimização desta escolha através da sua inclusão no modelo de programação linear inteira. Um outro âmbito é a generalização do modelo ao problema do reescalonamento da produção (escalonar de novo para ter em conta alterações ocorridas), problema estudado em Gomes (2007) e Gomes et al. (2010). Nesta indústria é muito comum existir a necessidade de corrigir moldes já finalizados, tornando-se necessário inserir no plano de produção operações de correção das peças; atualmente esta inserção não é feita de forma sistemática pelo diretor de produção da empresa. Outra situação a estudar é a inserção de novas encomendas (novos moldes) num plano existente, fazendo uso da capacidade disponível das máquinas.

Em conclusão, este projeto revelou-se promissor no que respeita ao fortalecimento da ligação entre a universidade e a indústria de moldes, podendo vir a proporcionar oportunidades de colaboração com a empresa 
GECO no desenvolvimento de uma ferramenta computacional de apoio ao planeamento e escalonamento da produção.

\section{Agradecimentos}

As autoras agradecem ao Sr. António Febra, diretor da GECO, a abertura e o incentivo à realização deste trabalho, recebendo a Bárbara Virgílio como estagiária na empresa, e ao Sr. Pedro Henriques, diretor de produção, e à sua equipa, todo o auxílio prestado no levantamento de dados bem como as orientações preciosas para a consecução do projeto. Foi com alegria e orgulho que as orientadoras viram a Bárbara Virgílio iniciar a sua vida profissional na GECO após a conclusão do Mestrado em Engenharia e Gestão Industrial do Instituto Superior Técnico, em novembro de 2011.

Agradecem ainda aos dois revisores anónimos pelas numerosas sugestões que permitiram melhorar este trabalho.

\section{Bibliografia}

A Indústria Portuguesa de Engineering and Tooling. (2010). Obtido em Outubro de 2010, do website da CEFAMOL: http://www.cefamol.pt .

CHOI, B. K. \& You, N. K. (2006). Dispatching rules for dynamic scheduling of one-of-a-kind production. International Journal of Computer Integrated Manufacturing, 19, 383-392.

CHOY, K.L., Leung, Y.K., Chow, H.K.H., Poon, T.C., Kwong, C.K., Ho, G.T.S. \& Kwok, S.K. (2011). A hybrid scheduling decision support model for minimizing job tardiness in a make-toorder based mould manufacturing environment. Expert Systems with Applications, 38, 1931-1941.

FLOUDAS, C. A. \& Lin, X. (2004). Continuous-time versus discrete-time approaches for scheduling of chemical processes: a review. Computers and Chemical Engineering, 28, 2109-2129.

GOMES, M., Barbosa-Póvoa, A. \& Novais, A.Q. (2005). Optimal scheduling for flexible job shop operation. International Journal of Production Research, 43, 2323-2353.

GOMES, C. (2007). Reactive scheduling in make-to-order production systems: An optimization based approach. Tese de Doutoramento em Engenharia de Sistemas, Instituto Superior Técnico, Universidade Técnica de Lisboa.

GOMES, M.C., Barbosa-Póvoa, A. \& Novais, A.Q. (2010). A discrete time reactive scheduling model for new order insertion in job shop, make-to-order industries. International Journal of Production Research, 48, 7395-7422.

IAPMEI (2006). A indústria portuguesa de moldes no contexto internacional - Contributos para o conbecimento da actividade. Rede de gabinetes de empresa do IAPMEI.

JAIN, A. S \& Meeran, S. (1999). Deterministic job shop scheduling: Past, present, future. European Journal of Operational Research, 113, 390-434 
LOPES, F. (2000). Retratos da indústria portuguesa de moldes para plásticos. Edição da Universidade do Minho: Braga.

MÉNDEZ, C. A., Cerdá, J., Grossmann, I. E., Harjunkoski, I. \& Fahl, M. (2006). State-of-the-art review of optimization methods for short-term scheduling of batch processes. Computers and Chemical Engineering, 30, 913-946.

NI, Q., Feng, L. W., Yarlagadda, P. K. \& Ming, X. (2007). Business information modeling for process integration in the mold making industry. Robotics and Computer-Integrated Manufacturing, 23, 195-207.

OzGuvEN, C., Ozbakir, L. \& Yavuz, Y. (2010). Mathematical Models for Job Shop Scheduling Problems with Routing and Process Plan Flexibility. Applied Mathematical Modelling, 34, 1539-1548.

PAN, J.C.-H. \& Chen, J.-S. (2005). Mixed binary integer programming formulations for the reentrant job shop scheduling problem. Computers and Operations Research, 32, 1197-1212.

POTTS, C. \& Strusevich, V. (2009). Fifty years of scheduling: a survey of milestones. Journal of the Operational Research Society, 60, S41-S68.

Plano Estratégico para o Sector dos Moldes em Portugal. (2008). Obtido em Janeiro de 2011, do website da Sociedade Portuguesa de Inovação: http://www.spi.pt/p.publicacoes .

TAY, J.C. \& Ho, N.B. (2008). Evolving dispatching rules using genetic programming for solving multi-objective flexible job-shop problems. Computers and Industrial Engineering, 54, 453-473.

VIRGÍllo, Bárbara E.S. (2011), Optimização do planeamento e escalonamento da produção na indústria de moldes: Aplicação ao caso da GECO. Dissertação de Mestrado em Engenharia e Gestão Industrial, Instituto Superior Técnico, Universidade Técnica de Lisboa. 


\section{Anexo}

Carta de Gantt correspondente ao plano de produção B1 (descrito na secção 5.1): carga das máquinas m1 a m9.

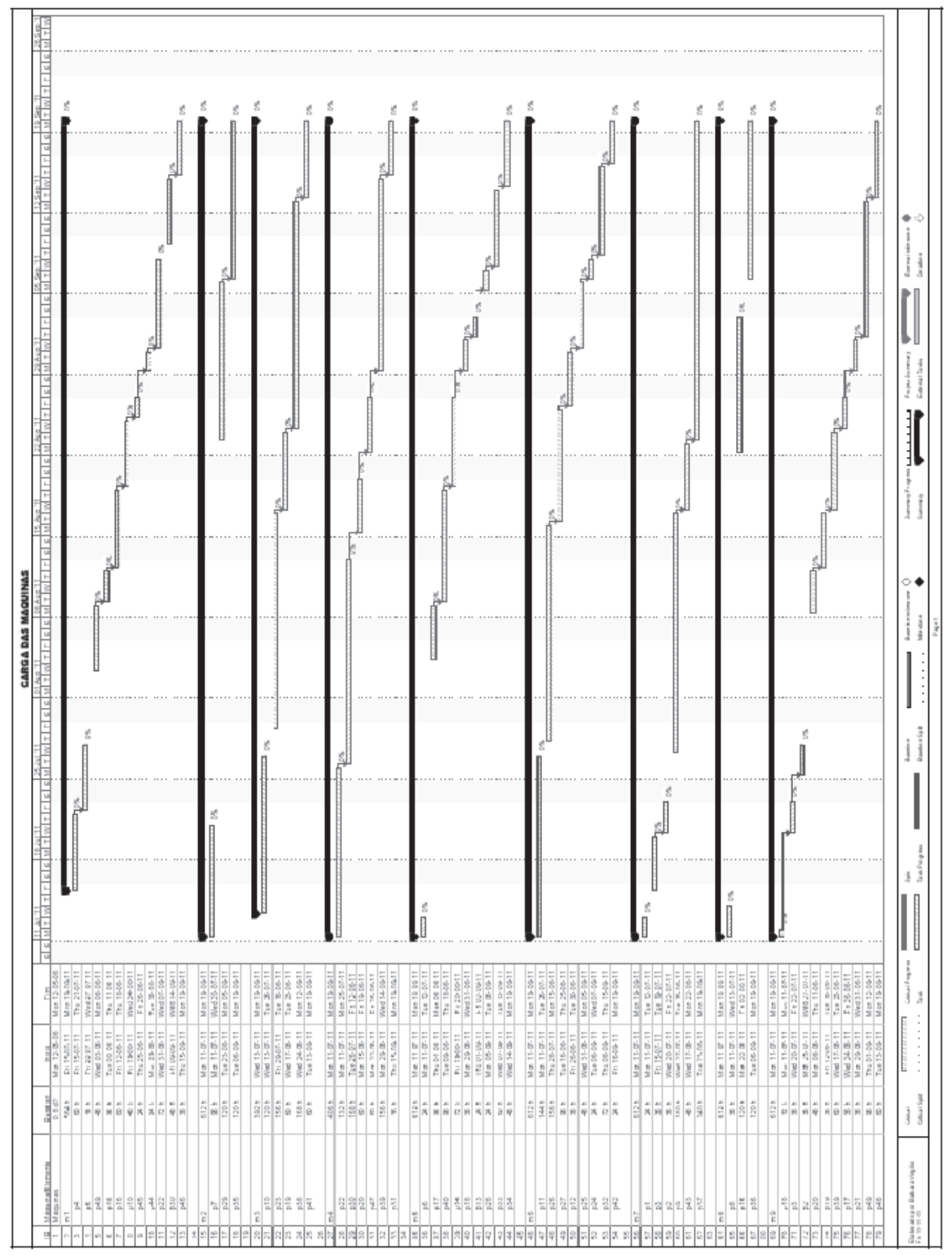

